\title{
Research Paper: Comparison of Responsiveness Status of Rehabilitation Services Organization From the Perspective of Services Recipients
}

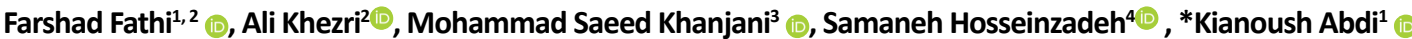

1. Department of Rehabilitation Management, University of Social Welfare and Rehabilitation Sciences, Tehran, Iran.

2. Iranian Center of Excellence in Health Management, Student Research Committee, School of Management and Medical Informatics, Tabriz University of Medical Sciences, Tabriz, Iran.

3. Department of Counseling, University of Social Welfare and Rehabilitation Sciences, Tehran, Iran.

4. Department of Biostatistics, University of Social Welfare and Rehabilitation Sciences, Tehran, Iran

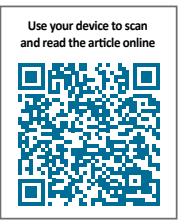

Citation Fathi F, Khezri A, Khanjani MS, Hosseinzadeh S, Abdi K. [Comparison of Responsiveness Status of Rehabilitation Services Organization From the Perspective of Services Recipients (Persian)]. Archives of Rehabilitation. 2019; 20(3):270-285. http://dx.doi.org/10.32598/rj.20.3.270

"http://dx.doi.org/10.32598/rj.20.3.270

Received: 07 Apr 2019

Accepted: $17 \mathrm{Jul} 2019$ Available Online: 01 Oct 2019

\begin{abstract}
A B STRACT
Objective Responsiveness is a process that all organizations, such as hospitals and rehabilitation centers, need to implement it in order to legitimize their activities; and on the other hand, the recipients of rehabilitation services as a citizen of the community have a special place. Therefore, the main purpose of this study was to determine and compare the response status of rehabilitation service providers from the perspective of People With Disabilities (PWD) and their families in Tehran in 2016.

Materials \& Methods The study is descriptive-analytical and cross-sectional. The statistical population of the study consisted of all people with disabilities and their families who received rehabilitation services (Red Crescent, Wellbeing, Private Sector) in 2017. Samples were collected from rehabilitation centers of 5 districts of Tehran, using available sampling. The questionnaire was distributed based on the Response Questionnaire (World Health Organization, 2000) and 357 samples were collected. Adults with physical and motor disabilities and families with children with physical disabilities were included in the study, as well as those with mental disabilities and those who did not wish to participate in the study, as well as incomplete and unread questionnaires. The questionnaire has eight domains and included 25 questions. The questionnaire was distributed among 11 rehabilitation specialists with $\mathrm{CVI}=0.91$ and the reliability of the questionnaire was confirmed by 30 questionnaires in four centers in two weeks with a correlation coefficient of 0.83 and Cronbach's alpha of 0.77 . Data were analyzed through descriptive statistics (mean and standard deviation) and inferential statistics (Mann-Whitney and Kruskal-Wallis) by using SPSS V. 22.

Results The results showed that the age of the majority of patients $(49.6 \%)$ was in the group of 30-39 years. Depending on the type of center, the mean age included $49.5 \%$ in private centers, $49.5 \%$ in the welfare centers, and $50 \%$ in Red Crescent. The highest responsiveness was related to the dimensions of the right to choose and environmental quality ( 2.6 and 2.41 out of 5 , respectively) in private centers, environmental quality (2.1 out of 5 ) in welfare centers, and then, right to choose had the highest score. The lowest accountability was reported for dignity ( 2.18 out of 5 ). The mean scores of social support dimensions in the three types of center were statistically different $(P=0.001)$, as well as the mean scores of immediate attention $(P=0.002)$, participation in decision-making $(P=0.009)$, confidentiality $(P=0.010)$, and total responsiveness $(P=0.04)$ there was a statistically significant difference between the two groups of referral type and mean scores of immediate attention dimensions in the
\end{abstract}

\section{* Corresponding Author:}

Kianoush Abdi, PhD.

Address: Department of Rehabilitation Management, University of Social Welfare and Rehabilitation Sciences, Tehran, Iran.

Tel: +98 (912) 7603800

E-Mail: k55abdi@yahoo.com 
Keywords:

Responsiveness, Rehabilitation, Recipients of service, People with disabilities, Family with disabilities two sex groups $(P=0.022)$. However, the mean scores of total responsiveness dimensions in marital status $(P=0.446)$ and type of insurance $(P=0.535)$ were not statistically significant.

Conclusion The findings of this study displayed that responsibility as a criterion of quality of rehabilitation services, in fact, provides a clear picture of the clients' performance. Responsibility of welfare centers was better than private and Red Crescent Centers. In this study, rehabilitation centers had the lowest performance in areas of transparent communication, dignity, and social support which may result in lower dignity which may indicate less attention to the dignity of the recipient of the service and the deficiency of insufficient insurance coverage to support rehabilitation services. While these dimensions of responsiveness are important for services recipients. Therefore, it is necessary to respond to the rehabilitation system in these areas (transparent communication, dignity and social protection). Also, it is recommended further studies in the area of responsiveness of rehabilitation system. 
This Page Intentionally Left Blank 


\title{
مقايسه وضعيت باسخخَويى سازمانهاى ار ائهدهنده خدمات توانبخشى از ديدكَاه دريافت كنندكًان خدمات
}

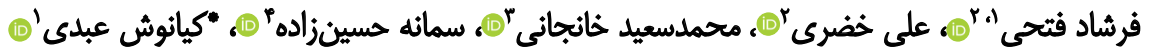

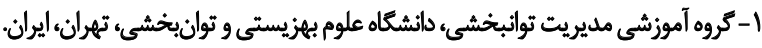

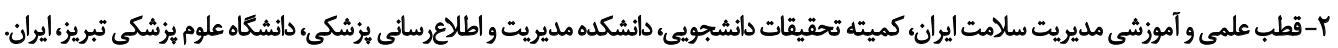

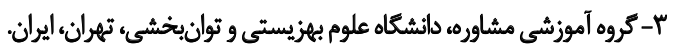

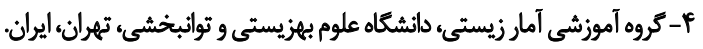

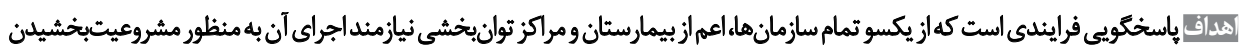

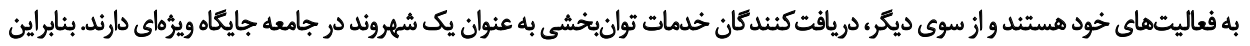

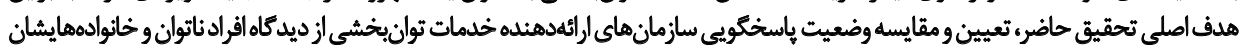

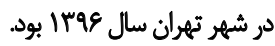

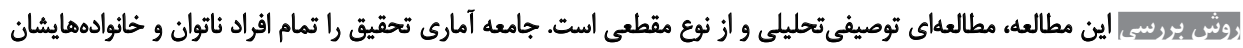

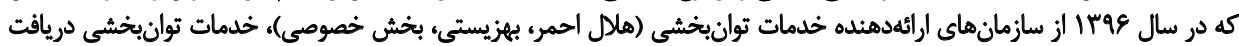

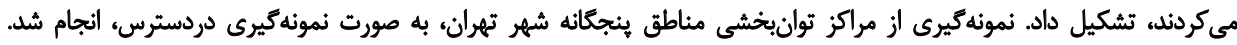

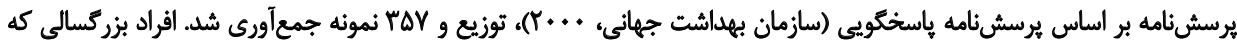

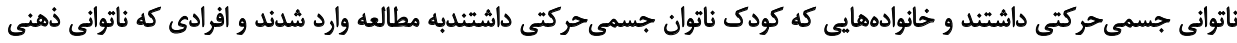

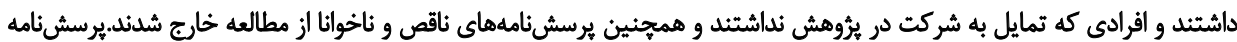

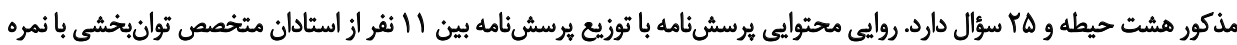

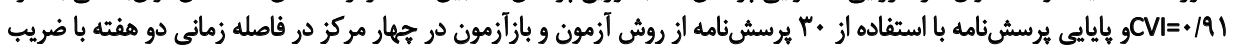

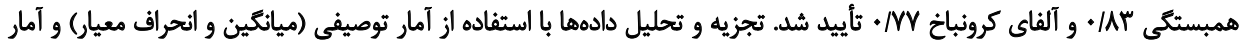

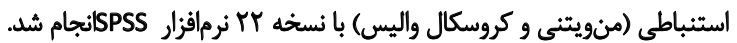

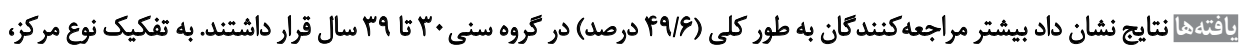

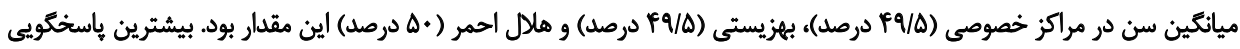

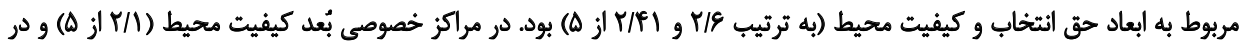

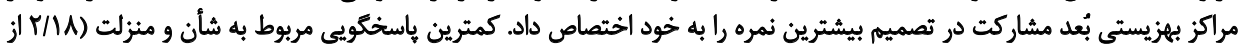

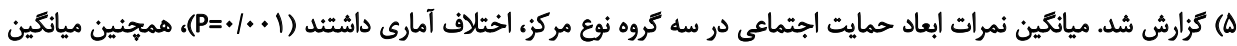

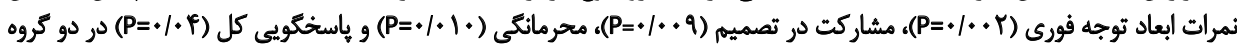

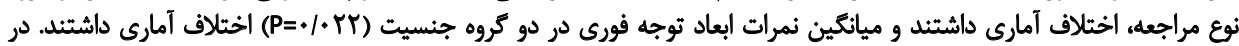

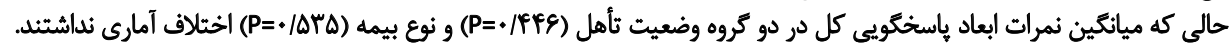

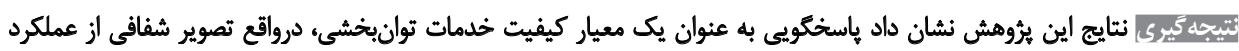

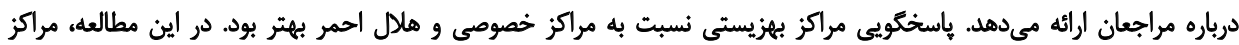

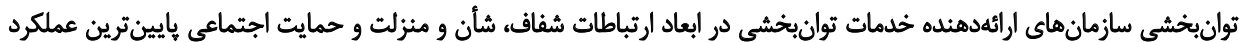

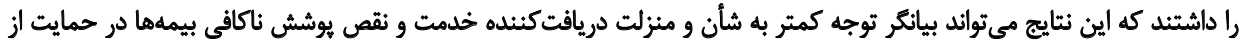

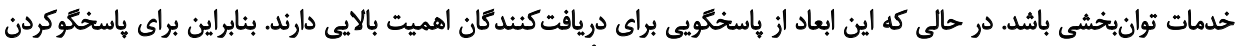

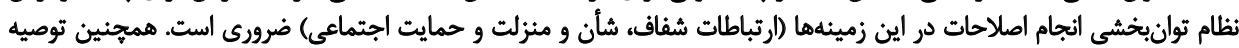

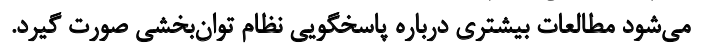
تاريخ انتشار: 9. مهر 149

$$
\begin{aligned}
& \text { كليدواروهها: } \\
& \text { ياسخَّويى، توانبخشى، } \\
& \text { دريافت كنيدكان } \\
& \text { خدمات، افراد داراي } \\
& \text { ناثوانى، خانواده داراى } \\
& \text { فرد ناتوان }
\end{aligned}
$$


واروه باسخكُويى، به معناي احساس مسئوليت، الزام و تعهد

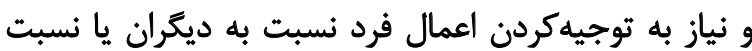

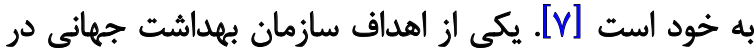

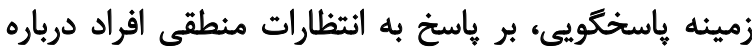

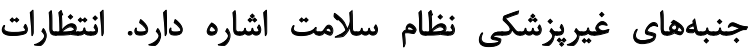

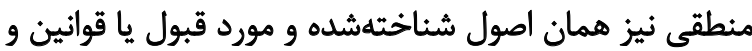

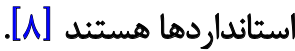

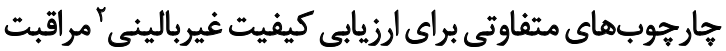

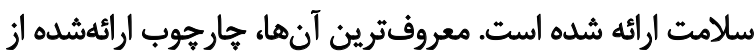

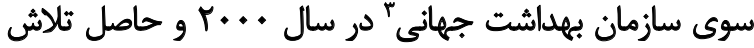

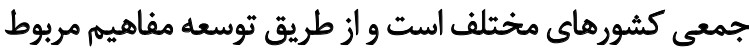

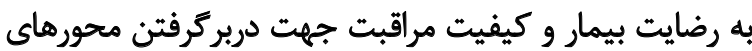

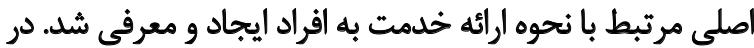

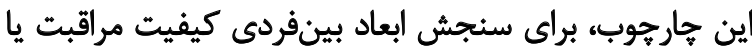

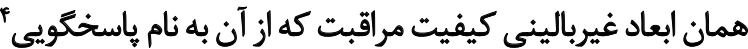

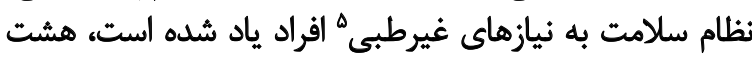

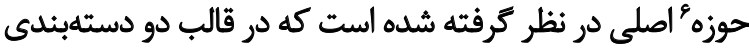

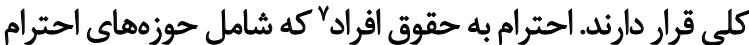

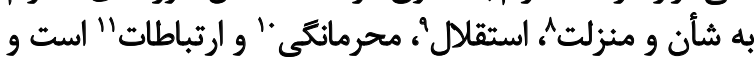

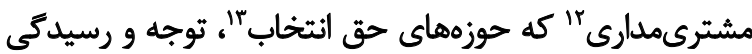

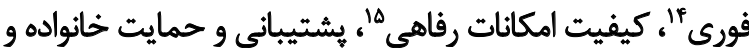

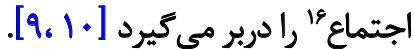

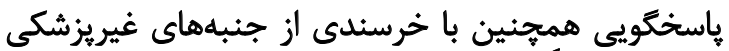

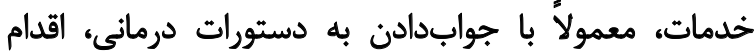

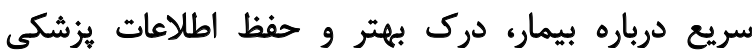

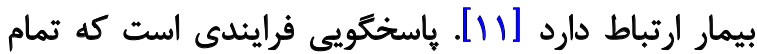

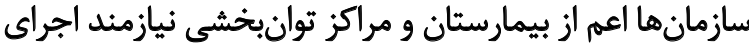

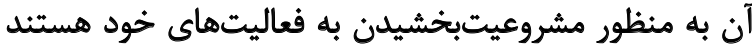

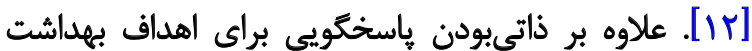

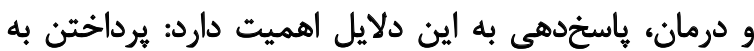

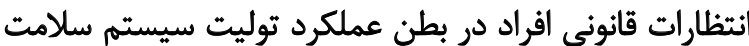

\section{Nonclinical}

3. World Health Organization (WHO)

4. Responsiveness

5. Nonclinical

6. Domain

7. Respect to person

8. Dignity

9. Autonomy

10. Confidentiality

11. Communication

12. Customer oriented

13. Choice of health care provider

14. Prompt attention

15. Quality of basic amenities

16. Access to social support
فضاى بيجيده و رقابتى جهان امروز، سازمانها را به سوى سرى

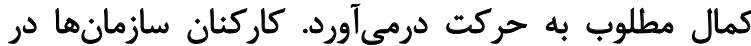

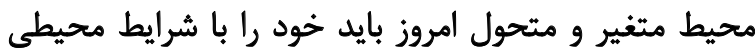

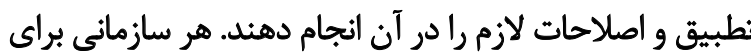

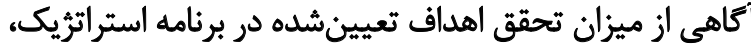

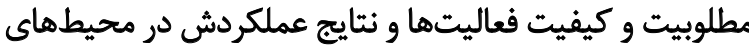

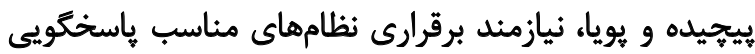

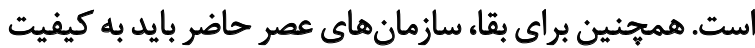

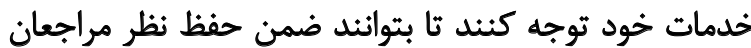

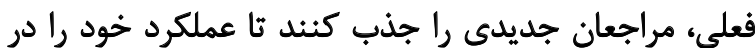

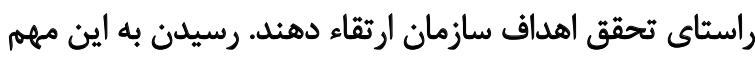

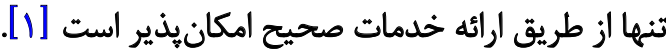
توانبخشى يكى از مؤلفههاى سلامت است و در دهاهماى

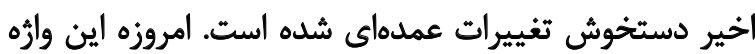

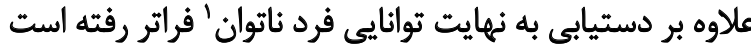

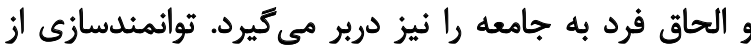

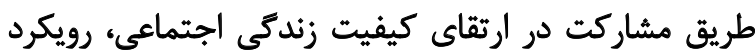

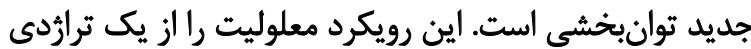

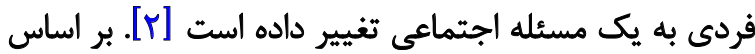

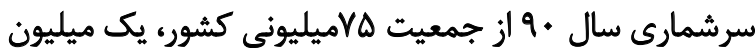

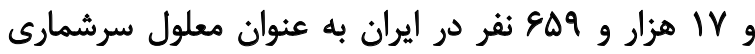

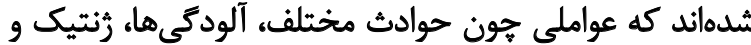

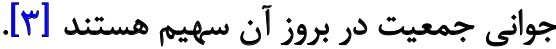

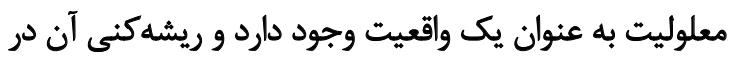

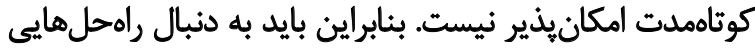

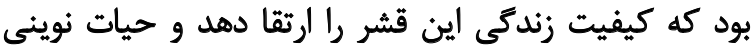

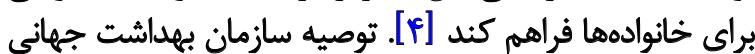

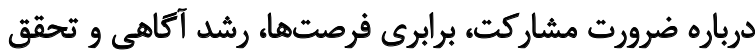

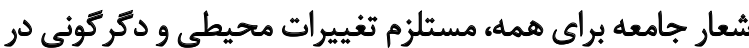

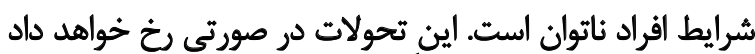

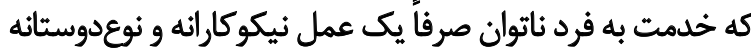

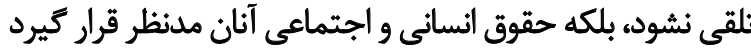

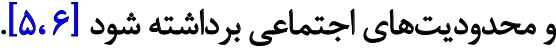
اساس خدمات توانبخشى را از يكسو شناخت انتظارات و

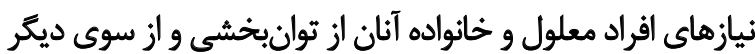

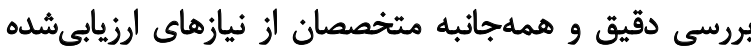

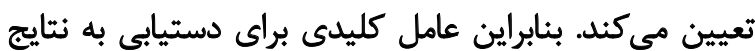

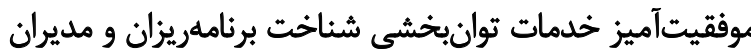

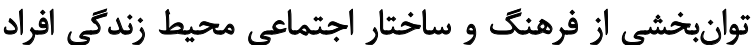

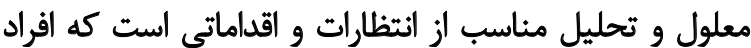

1. People with disability 
سلامت و در يك جمله در كل كشور حائز اهميت است. بنابراين

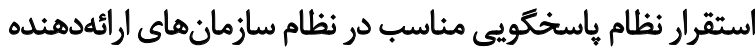

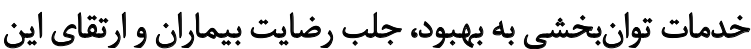
خدمات كمك شايانى مى كند.

از آنجايى كه به نظر ميرسد به وضعيت ياسختحويى در

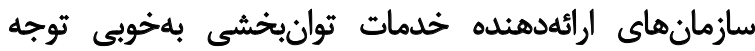

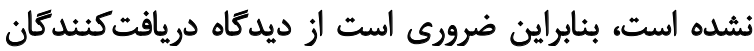

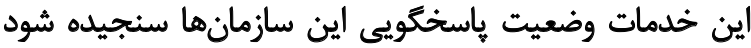

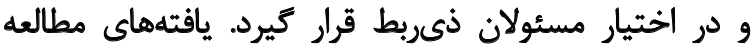

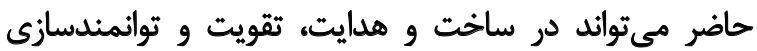

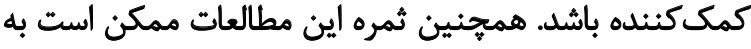

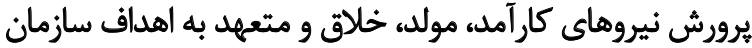

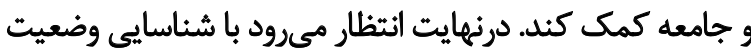

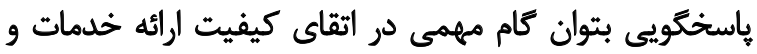

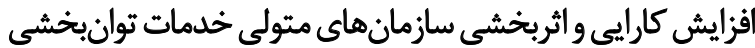

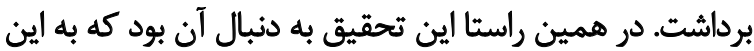

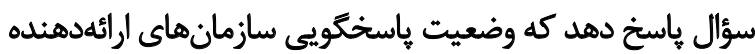

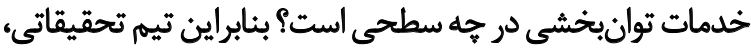

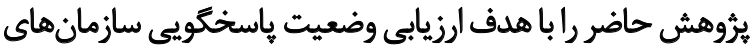

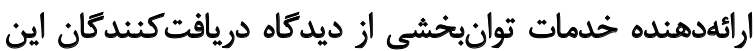

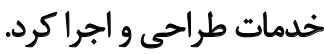

\section{ووشي بروسي}

اين مطالعه، مطالعهاى توصيفى تحليلى واز نوع مقطعى است.

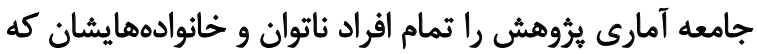

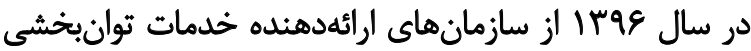
(هلال احمر، بهزيستى، خصوصى)، خدمات درئ دريافت إنت كردهاند،

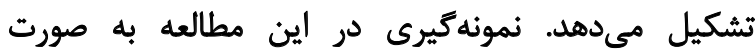

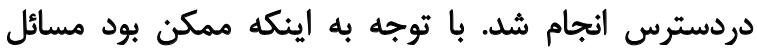

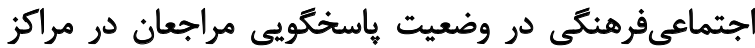

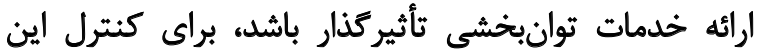

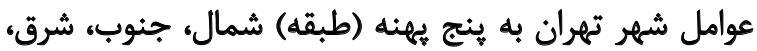

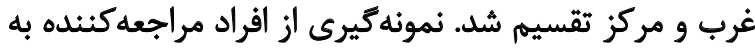

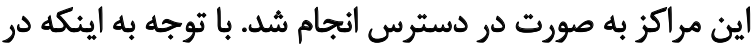

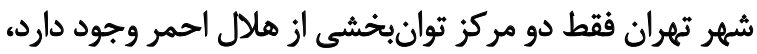

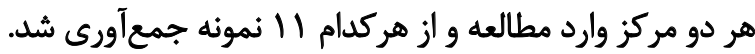

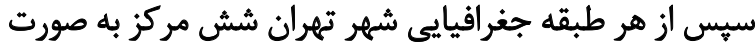

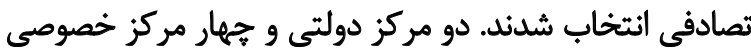

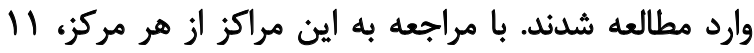
نمونه به صورت دردسترس انتخاب و در مطالعه وارد شدند.

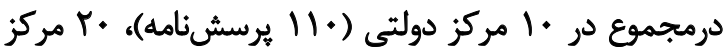

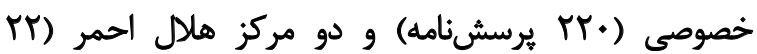

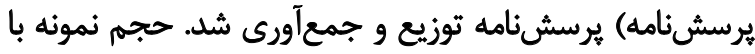

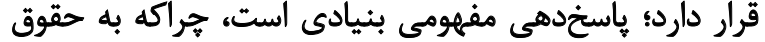

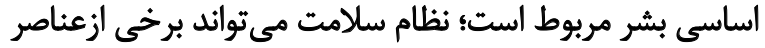

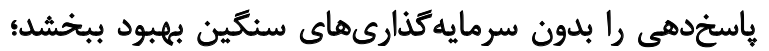

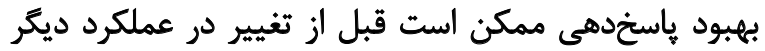

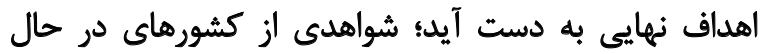
توسعه وجود دارد مبنى بر اينكه بيماران دان راضى الئ احتمال

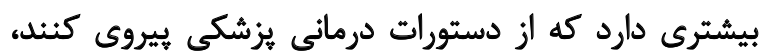

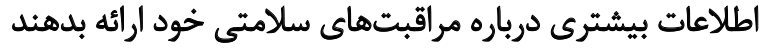

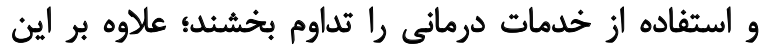
ارتقاى ياسخدهى مي تواند باعث افزايش احساس آسايش و نيز آنيز

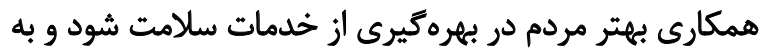

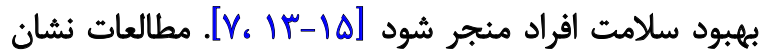

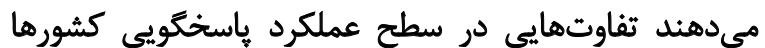

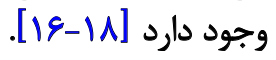

مراكز و سازمانهاى ارائهدهنده خدمات توانبخشى با توجه بـ فيه

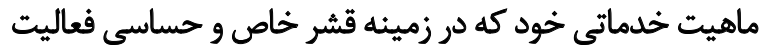

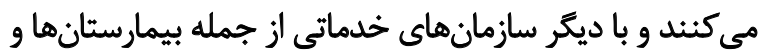

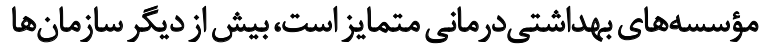

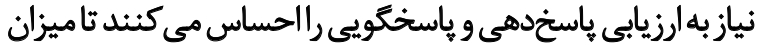

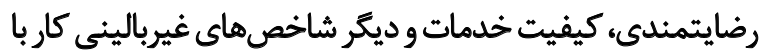

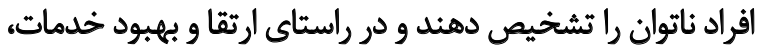
برنامهريزى و سياست كذارى كنئد [19]

رضايتمندى از سيستم سلامت و پاسختكويى به جنبههاى

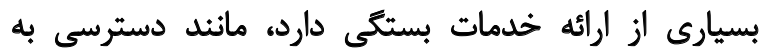

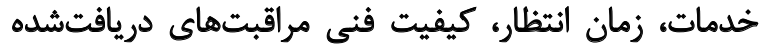

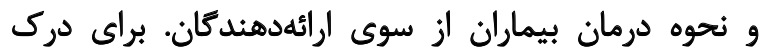

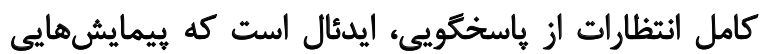

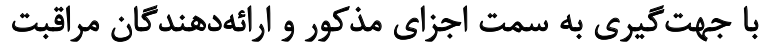

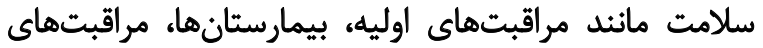

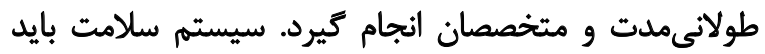

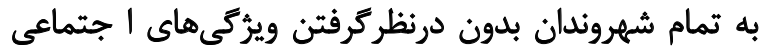

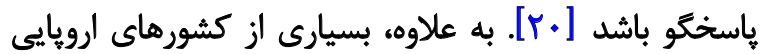

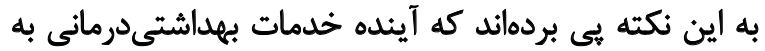

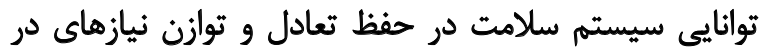

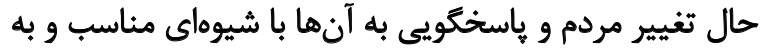

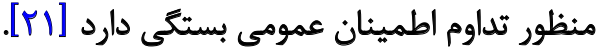

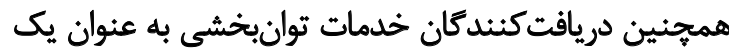

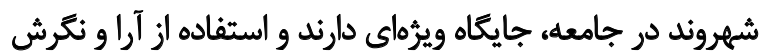

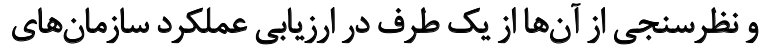

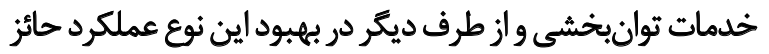

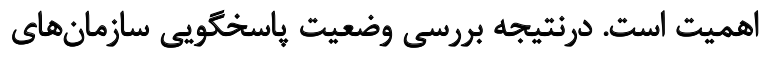

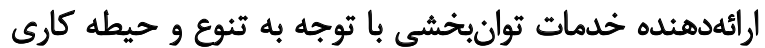

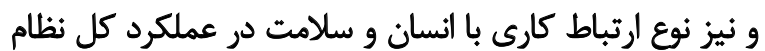




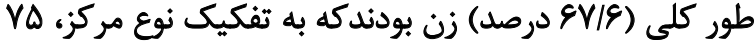

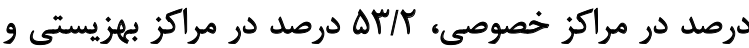

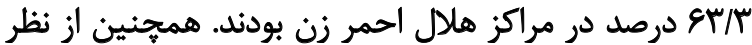

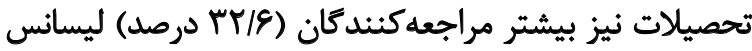

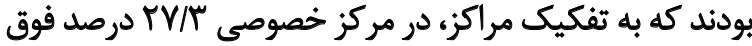

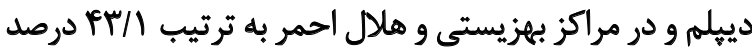

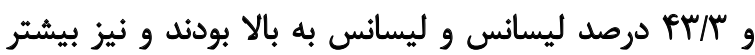

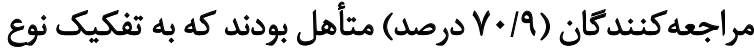

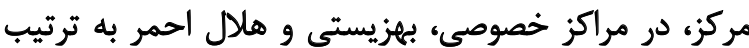

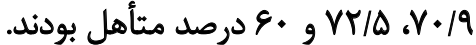

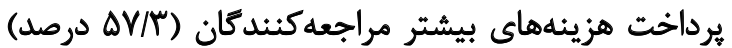

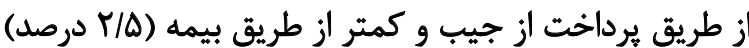

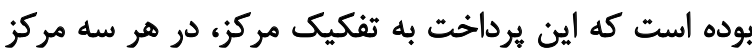

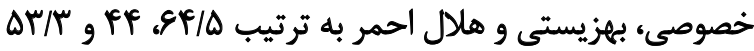

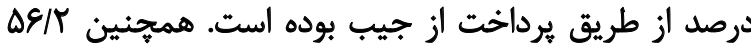

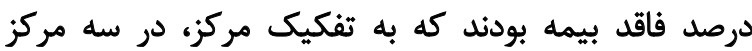

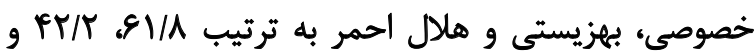

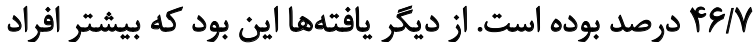

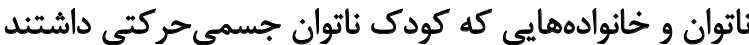
(AV/T)

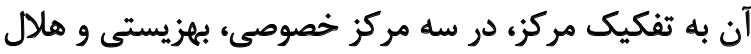

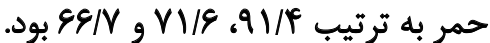

بر اساس جدول شماره Y بيشترين باسختويى مربوط بر به ابعاد

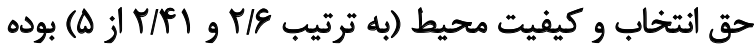

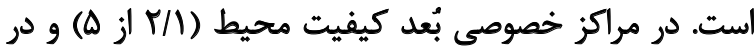

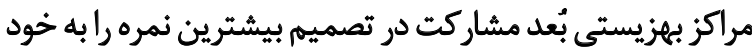

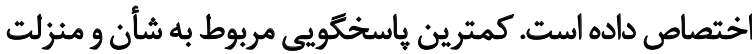

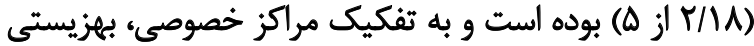

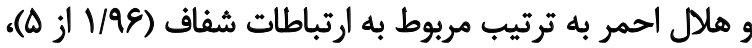

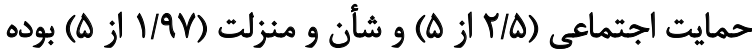

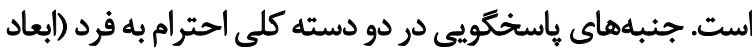

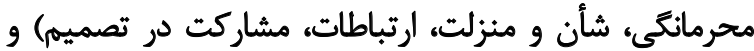

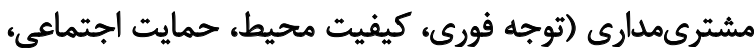

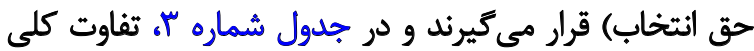

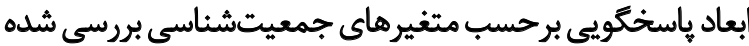

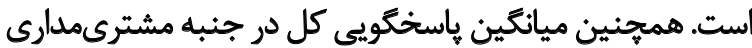

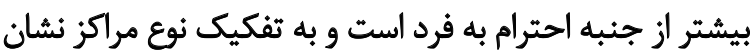

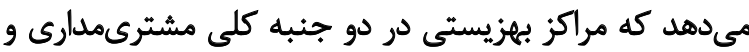

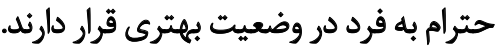

بر اساس نتايج جدول شماره با، هشت بُعد ياسخكويى (نوع

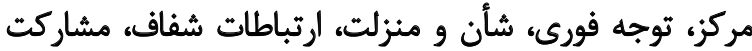

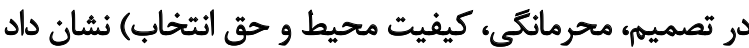

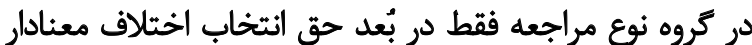

استناد بر مطالعات مشابه و بر اساس فرمول كوكران با اطميئان

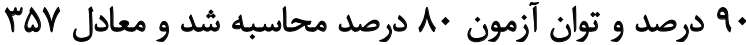

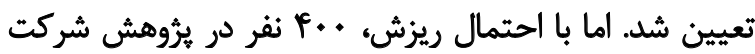

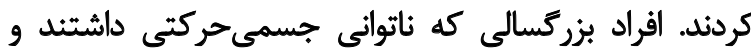

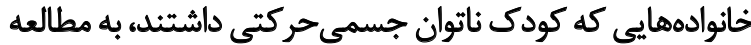

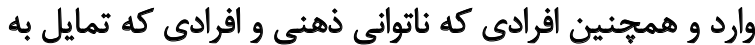

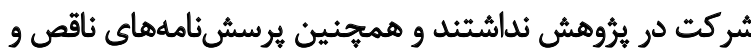

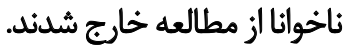

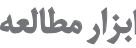

در اين مطالعه از يرسشنامه بِاسخكويى (سازمان بهداشت

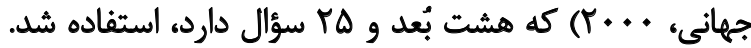

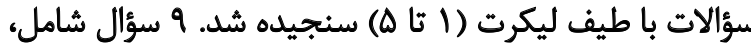

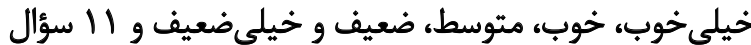

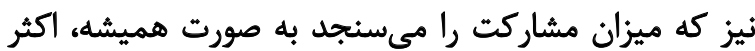
اوقات، كاهي، تا حدودى و هيجوقت بودند.

در اين بُروهش، به منظور بررسى روايى محتوايى، برسش ناميه

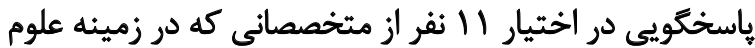

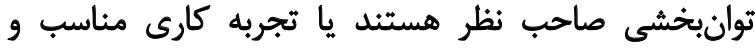

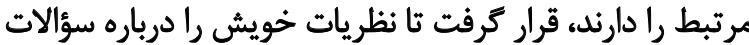

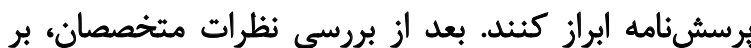

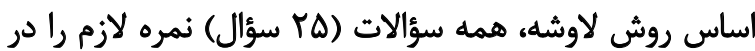

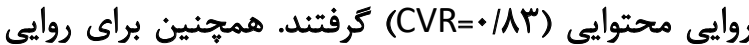

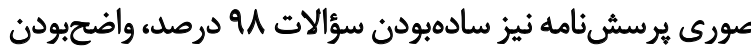

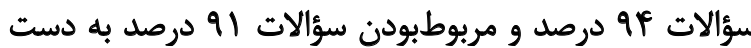

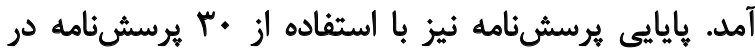

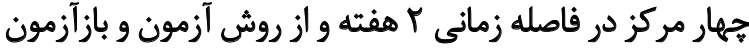

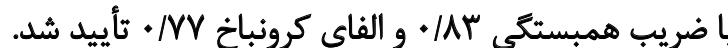

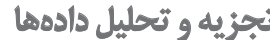

بدين منظور براى تجزيه و تحليل دادهها از آزمونهاي آمار

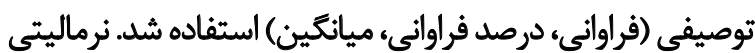

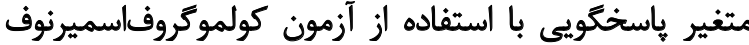

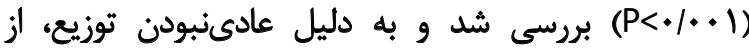

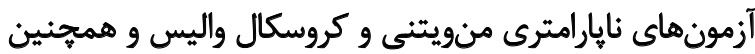

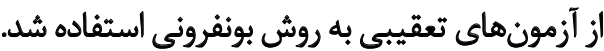

يافتهها

نتايج حاصل از جدول شماره 1 حاكى از آن است كه آند

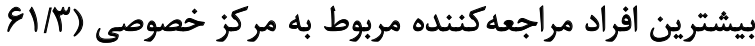

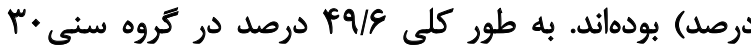

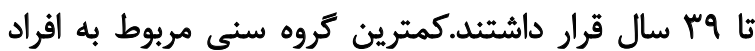

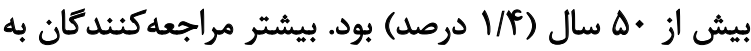


جدول ا. توزيع فراوانى ويرُكى هاى فردى دريافت كنيدكان خدمات از مراكز سازمان هاى ارائهدهنده خدمات توانبخشى

\begin{tabular}{|c|c|c|c|c|c|}
\hline \multicolumn{4}{|c|}{ تعداد(درصد) } & \multirow{2}{*}{\multicolumn{2}{|c|}{ مثغيير }} \\
\hline كل مراكز & مراكز خُصوصي & مراكز بهزيستى & مراكز هلال احمر & & \\
\hline $\operatorname{MrT}(\mathscr{N V T})$ & $\mid E A(f \& / N)$ & $\Delta M(1 E / T)$ & $19(\Delta / \pi)$ & ن & \\
\hline$\| \varepsilon(\pi T / F)$ & $\Delta \Delta\left(1 \Delta / \varphi^{\circ}\right)$ & $\left.\Delta \cdot(1)^{+}\right)$ & $11(r /)$ & مرد & 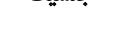 \\
\hline ११(Tه/T) & $\Delta \Delta(1 \Delta / \psi)$ & rAp/q) & $A(T / T)$ & r.-rq & \\
\hline $\operatorname{IrA}(p 9,9)$ & $A r(T r / T)$ & एव(11) & $\| r(r / N)$ & 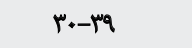 & \\
\hline$N A(T M / M)$ & $V \cdot(19 / 1)$ & $r g(V / N)$ & $V(r)$ & $p=-p q$ & سن \\
\hline$\Delta(1 / F)$ & $\operatorname{Ir}(r / M)$ & $\|(\% / 1)$ & $r(\cdot / \Lambda)$ & $\Delta \cdot \leq$ & \\
\hline$g+(I F / N)$ & $\Delta r(I F / \Delta)$ & $\Delta(1 / F)$ & $r(+/ \Lambda)$ & 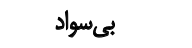 & \\
\hline$N A(T T / M)$ & $\Delta(1) / \pi)$ & $r E(V / T)$ & $A(T / T)$ & دييله & \\
\hline qY(TV) & $8 \cdot(1 E M)$ & MINE) & $f(M)$ & فوق دييلم & Sa \\
\hline$\| V(\pi / S)$ & $\Delta V(1 \Delta / 9)$ & $\operatorname{Rv}(1 \% /)$ & $1 \pi(r / 8)$ & ليسانس و بالاتر & \\
\hline $1 . f(T q /)$ & $\mathscr{R T}\left(I Y / T^{e}\right)$ & $r \cdot(A N)$ & $\| r(r / F)$ & مجرد & . \\
\hline $\operatorname{rar}(V \cdot / 9)$ & $1 D F(M T / M)$ & Va(TT/) & $W(\Delta)$ & متأهل & \\
\hline$r+g(\Delta V / F)$ & $\operatorname{lit}(r q / g)$ & $P A(I T / P)$ & $\theta(f / \Delta)$ & برداخت از جيب & \\
\hline $10(\% / T)$ & $9(T / \Delta)$ & $r(\cdot / \Lambda)$ & $r(\cdot / A)$ & بيمه & نوع يرداخت \\
\hline $\mathbb{H N}(T N F)$ & $89(19 / 7)$ & $\Delta M(18 / \pi)$ & $W(r / 1)$ & از جيب و بيمه & \\
\hline $9 q(19 / 1)$ & rA(1./9) & $r r(g / \pi)$ & $q(Y / 8)$ & كايه & \\
\hline $\operatorname{AF}(T+/)$ & $P F(I r / q)$ & $r \Delta(1 \cdot)$ & $\Delta\left(1 / T^{*}\right)$ & مكمل & ثوع بيمه \\
\hline $12 \varepsilon(\Delta \rho / \pi)$ & Ire(m) & $r(I r / T)$ & $I f(f)$ & فاقد ييمه & \\
\hline หจ१(AV/T) & $Y \cdot 1(\triangle N E)$ & VAPTM & $r \cdot(\Delta / A)$ & شخصى & \\
\hline$\mu F(I T / A)$ & $\Delta(1 / \Delta)$ & $r q(N A)$ & $1 \cdot(r / 9)$ & غُيرشخصى (ارجاع) & \\
\hline
\end{tabular}

توانبخننى

كمترين ميزان اختلاف آمارى بين كروههاى نوع بيمه

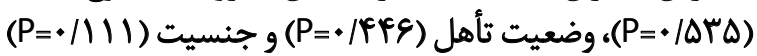

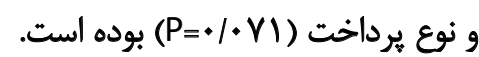

نتايج حاصل در جدول شماره f نشان داد ميانكين شأن و

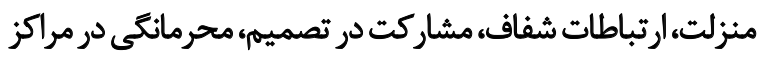

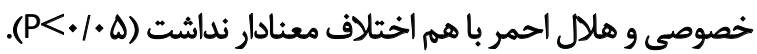

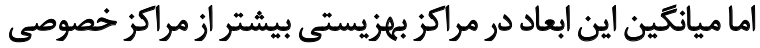

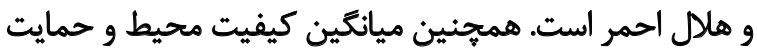

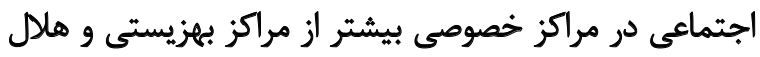

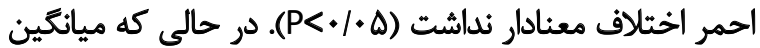

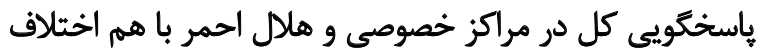

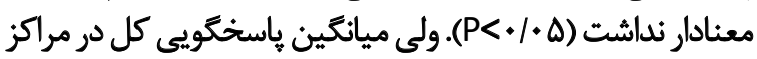

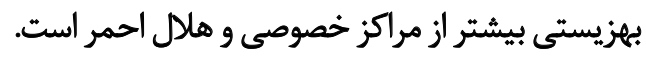
بر اساس تصوير شماره 1 بالهميترين بُعد از نظر
يافت شد (P= (P) و و در كروههاى نوع بيمه و وضعيت تأهل

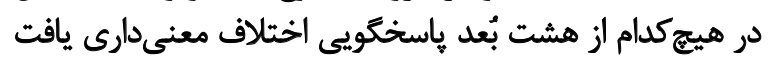

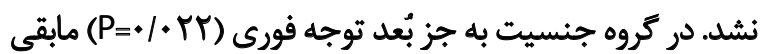

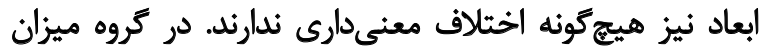

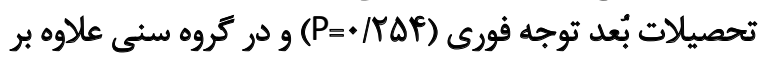

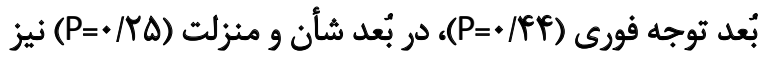

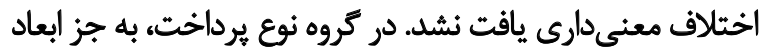

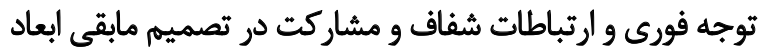

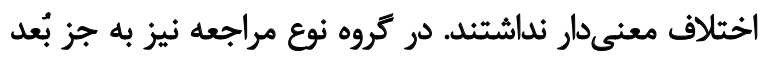

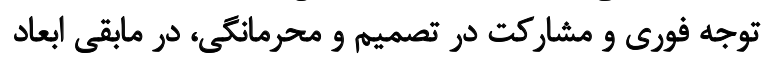
اختلاف معنى دارى يافت نشد.

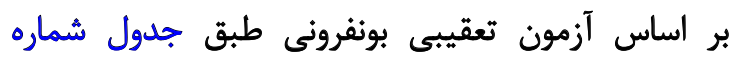

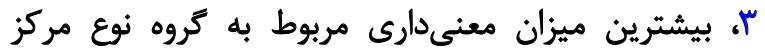

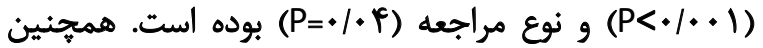


جدول r. ميانكين نمرات ابعاد ياسخكويى مراكز توانبخشى به تفكيك سازمانهاى ارائهدهنده خدمات توانبخشى

\begin{tabular}{|c|c|c|c|c|c|c|c|c|c|}
\hline \multicolumn{2}{|c|}{ كل مراكز } & \multicolumn{2}{|c|}{ مراكز خصوصى } & \multicolumn{2}{|c|}{ مراكزبيهزيستى } & \multicolumn{2}{|c|}{ مراكز هلالل احمر } & \multirow{2}{*}{\multicolumn{2}{|c|}{ توع مركز }} \\
\hline التمرافيكينيار & مياكه & اتحريافتمعيار & مياله & اتحمرافتمعيار & ميثله & التحرافمعيار & مياله & & \\
\hline$Y / T \pm \cdot / A \Delta$ & $r / \pi$ & $r / . . \pm . / 9 t$ & V/aY & $r / \cdot . \pm \cdot / A r$ & $r \% \vee$ & $r / \Delta \cdot \pm \cdot / \Lambda T$ & T/ & توجه فورى & \\
\hline$r \pm \cdot / A r$ & $\mathrm{TMA}$ & INDI.NT & 1/a & $r / N \Delta \pm \cdot / A Y$ & T/T & $r / \ldots \pm+N q$ & lav & شأن ومثزلت & \\
\hline$r / T \Delta \pm . / 9$. & $T / M$ & $Y / . . \pm \cdot N \Delta$ & $1 / 9$ & $r / \cdot \pm \pm / A r$ & $r / \%$ & $r / T \Delta \pm+/ 9 q$ & $r / T r$ & ارتباطات شفاف & \\
\hline$Y / T Y \pm=/ 9$. & $r / M r$ & $Y / \cdot \pm \pm N \Delta$ & $r / . r$ & $r / \cdot \pm \cdot / V \Lambda$ & $r / 1$ & $r / T T \pm \cdot M$ & $r / M$ & تشميمت در & البعادياسخكويى \\
\hline$Y / M T \pm \cdot / N$ & $r / r q$ & $Y / . . \pm \cdot N$. & $r / * 1$ & r/GE士./Q. & $r / N$ & $r / T I \pm \cdot M$ & $r / r r$ & محرماتكى & \\
\hline r/FF士./DI & $r / 9$. & $r / 99 \pm+/ \Delta 8$ & $r /+9$ & $r / \& \& \pm+/ F \mid$ & $r / \Delta 9$ & $r / 99 \pm+/ M q$ & $r / 9 \Delta$ & حق انتخاب & \\
\hline$T / T T \pm \cdot / N$ & $r / P$ & $Y / \cdot \pm \pm N \Delta$ & $r / 1$ & $r / \cdot \pm \cdot N A$ & $r \%$ & $T / T+N . N$. & $r / r A$ & كيفيت محيط & \\
\hline$r / \Delta \pm \cdot / 9$. & $r / M)$ & $Y / \cdot \pm \cdot / M$ & $r / I Y$ & $r / \Delta \pm . / 9)$ & $r / \Delta$ & $Y N \pm \cdot / M$ & $r / F$ & حمايت اجتماعى & \\
\hline$r / r q \pm \cdot / N A$. & T/TA & $r / . . \pm / q \gamma$. & V/Ar & $r / Y \backslash \pm / \mathscr{Q V}$ & $r / A Y$ & $r / / Y \pm . / 90$. & r/TA & احترام به فرد & \\
\hline$r / \mathscr{A} \mid \pm \cdot / \Delta \Lambda$. & $r / P I$ & $r / T I \pm / \Delta P$. & $r / \cdot \Lambda$ & $r / A \backslash \pm \cdot / F \&$ & r/Ar & $r / A s \pm . / \Delta .$. & $r / \Delta$. & مشترى مدارى & ياسخكويى \\
\hline
\end{tabular}

توانبخننى

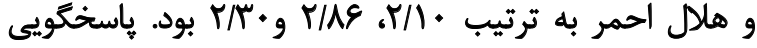

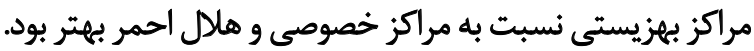

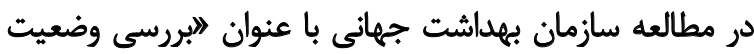

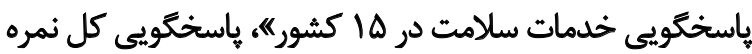

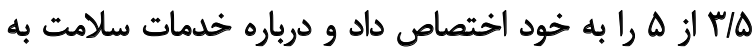

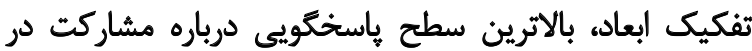

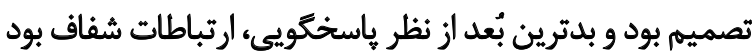

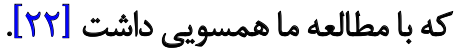
در مطالعه بلتزر"ا و همكاران با عنوان "هاسخكويى نظام 17. Peltzer

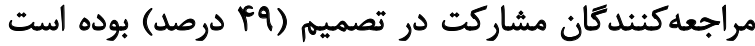

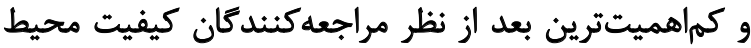

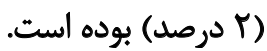
بحث

هدف از انجام مطالعه، بررسى و مقايسه وضعيت پاسخخَويى دريى

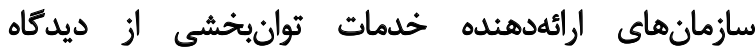

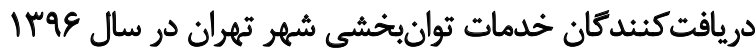

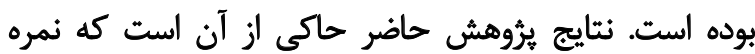

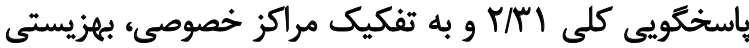

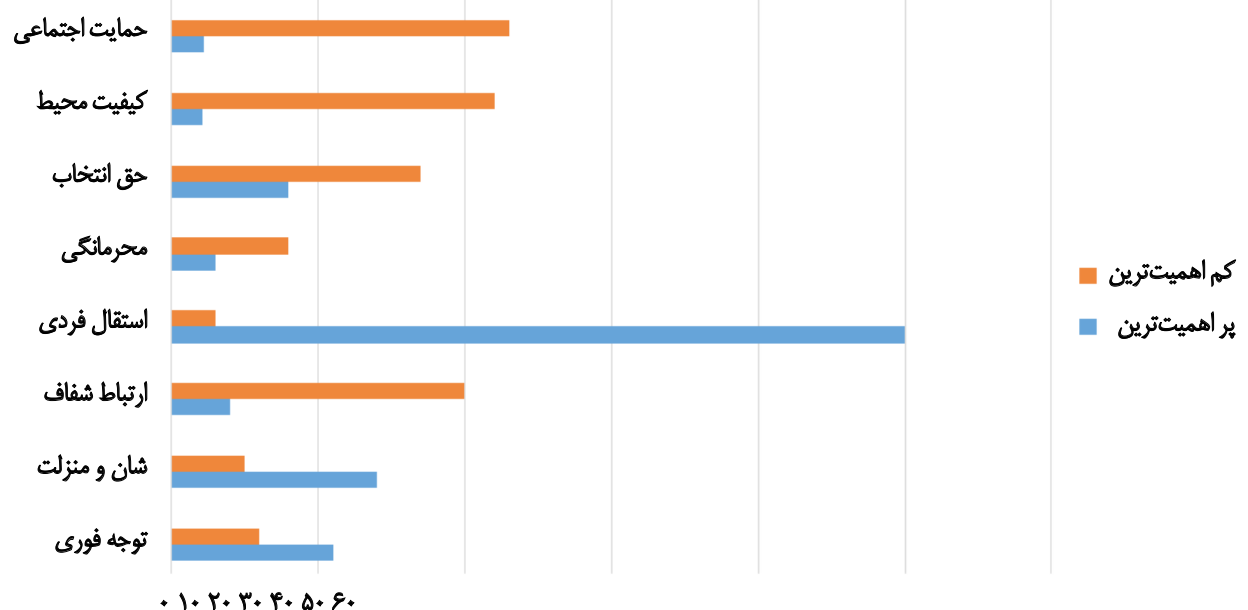




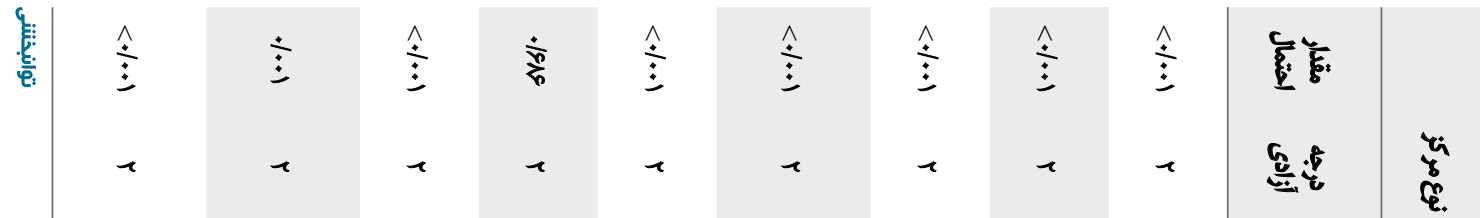

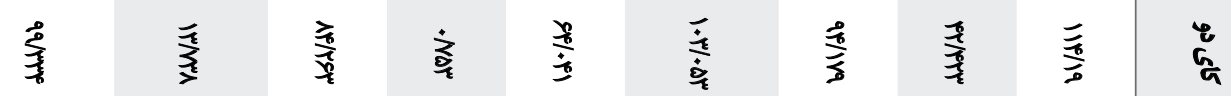

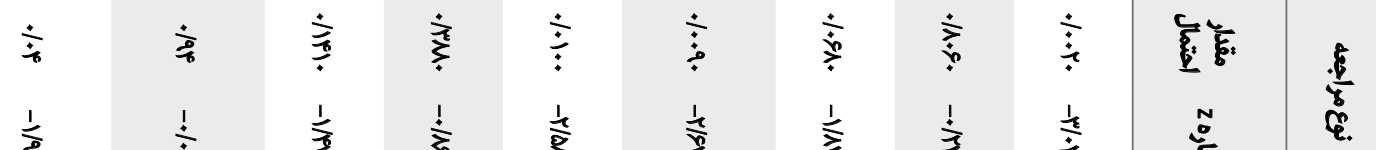

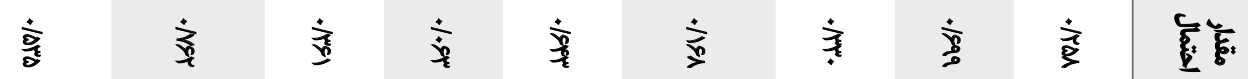
$++1+++$ + + +

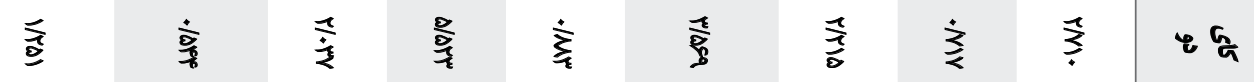

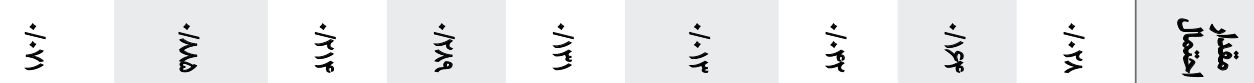
++++++++ + + +

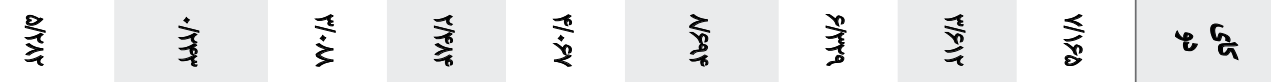

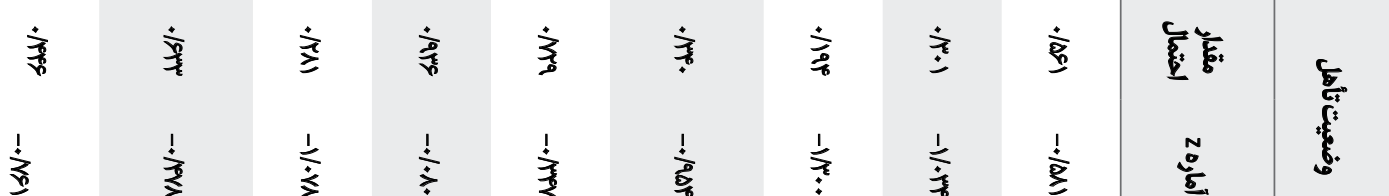

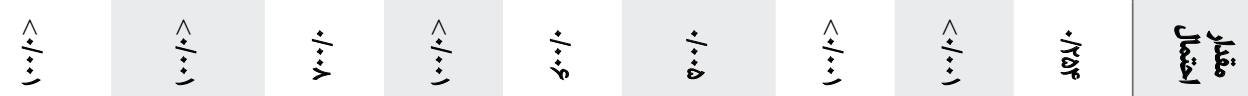

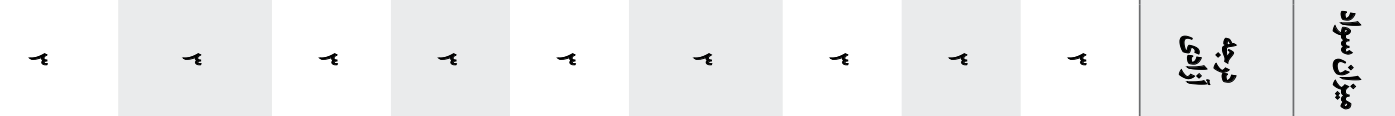

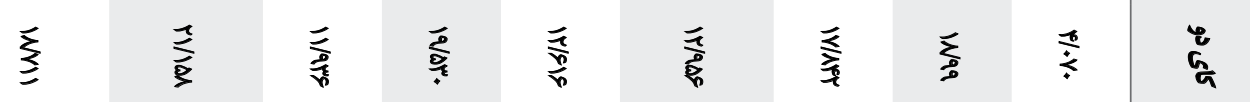

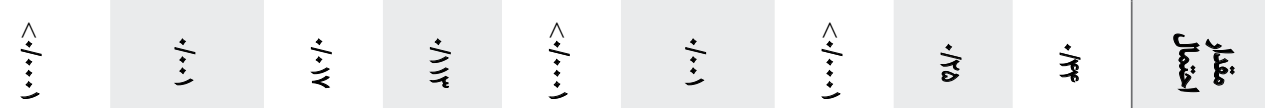

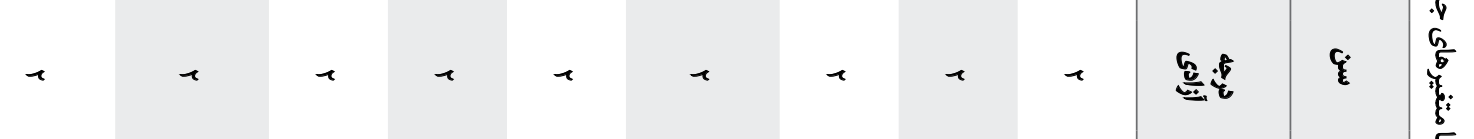

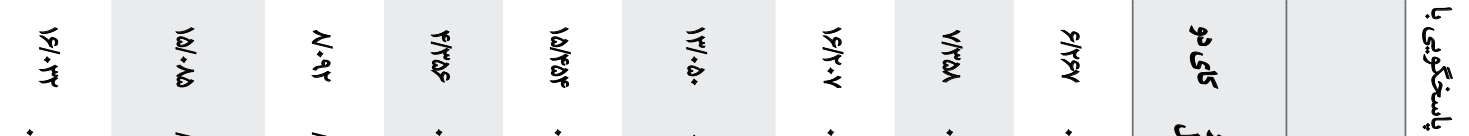

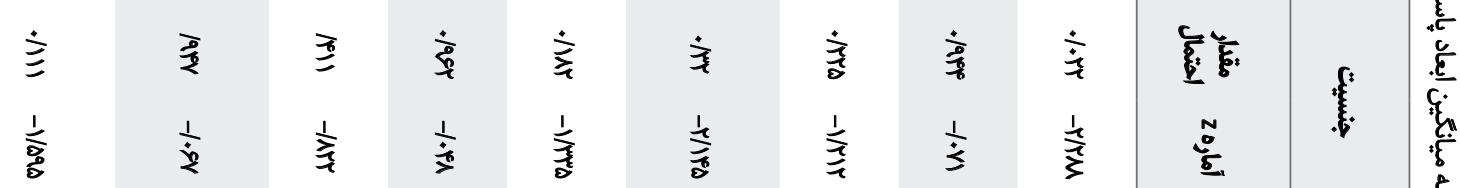

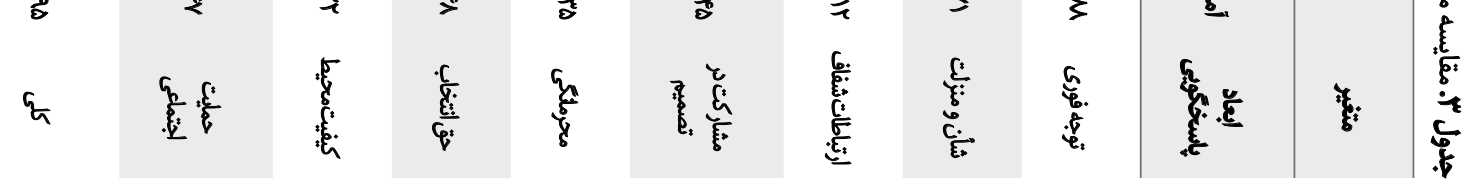


جدول ع. مقايسه زوجى ميائكينها به تفكيك مراكز سازمان هاى ارائهدهنده خدمات توانبخشى

\begin{tabular}{|c|c|c|c|c|}
\hline خصوصى و هلال احمر & بهزيستى و هلال احمر & بهزيستى وخصوصى & مقايسه مراكز & \\
\hline $\begin{array}{c}-+1.0 \\
1\end{array}$ & $\begin{array}{l}.184 \\
<.1 .+1\end{array}$ & $\begin{array}{r}+191 \\
<+1 .+1\end{array}$ & تفاوت ميانكينها & شأن و منزّلت \\
\hline $\begin{array}{l}-+n \\
+1+1\end{array}$ & $\begin{array}{l}\cdot N A \\
<\cdot 1 \cdot \cdot 1\end{array}$ & $\begin{array}{l}1 / * 1 \\
<+1 \cdot+1\end{array}$ & تثفاوت ميانكينها & ارتباطات شفاف \\
\hline $\begin{array}{l}-. / 19 \\
. / 01\end{array}$ & $\begin{array}{l}\cdot / M \\
<+1 \cdot+1\end{array}$ & $\begin{array}{l}1 / \cdot V \\
<\cdot 1 \cdot .1\end{array}$ & تفاوت ميانكينها & مشاركت در تصميم \\
\hline $\begin{array}{l}-. / 4 a \\
. / 48\end{array}$ & $\begin{array}{l}.|8| \\
<.1 .+1\end{array}$ & $\begin{array}{l}.10 \\
<+10.1\end{array}$ & تفاوت ميانكينها & محرمانكى \\
\hline $\begin{array}{l}-. / M \\
. \\
+\pi\end{array}$ & $\begin{array}{c}\cdot N \\
<+/ *+1\end{array}$ & $\begin{array}{l}. / 94 \\
<+/ *+1\end{array}$ & تفاوت ميانكينها & كيفيت محيط \\
\hline $\begin{array}{l}-+/ 21 \\
. / r\end{array}$ & $\begin{array}{c}.1 . r \\
1\end{array}$ & 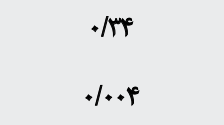 & تفاوت ميانكينها & حمايت اجتماعى \\
\hline $\begin{array}{l}-. / \pi r \\
.1 .8\end{array}$ & $\begin{array}{l}. / \Delta H^{\prime} \\
<+1 .+1\end{array}$ & $\begin{array}{l}. / N 8 \\
<+1 . .1\end{array}$ & تفاوت ميانكينها & ياسختكويى \\
\hline
\end{tabular}

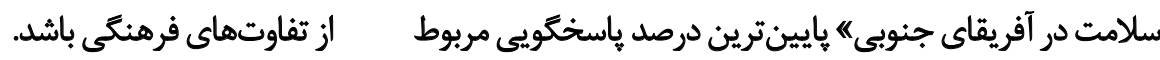

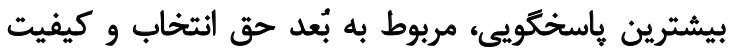

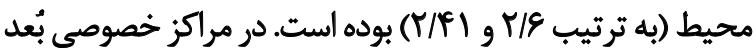

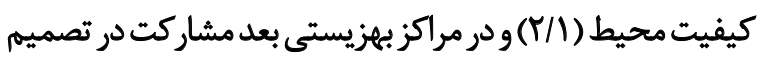

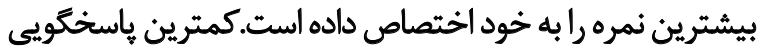

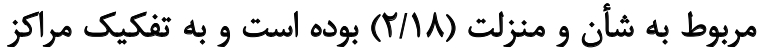

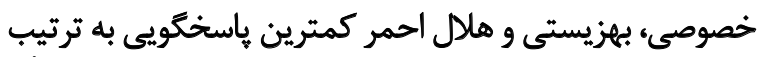

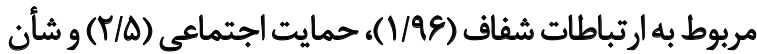

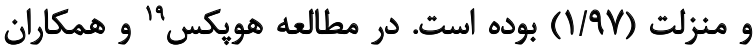

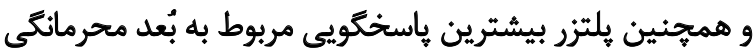

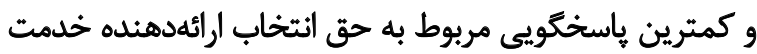

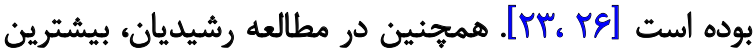

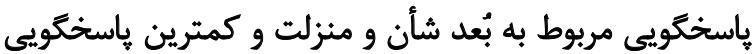

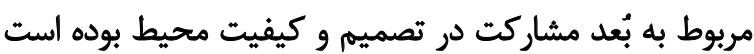

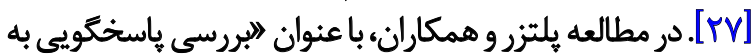

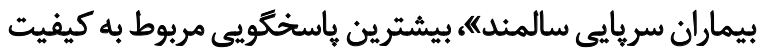

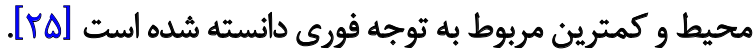
در مطالعه سازمان بهداشت جهائى در •ا مشور مربوط به بهاري

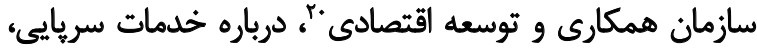

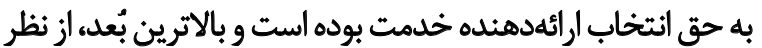

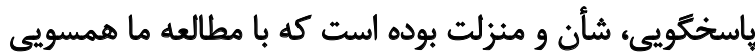

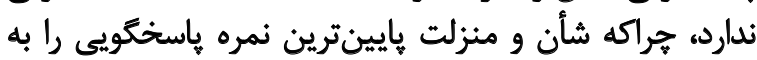

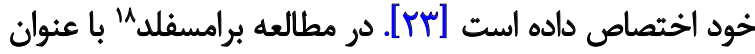

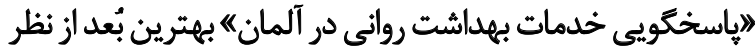

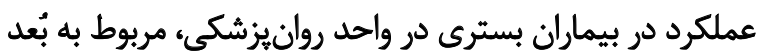

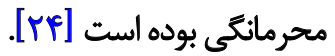
ارزيابى مراقبتهاى بسترى در مطالعه يُلتزر نشان داد مشاركت

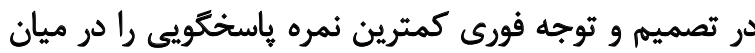

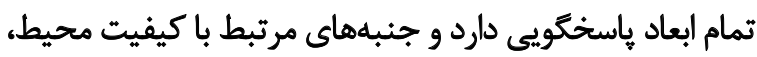

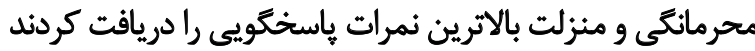

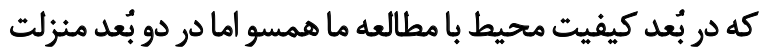

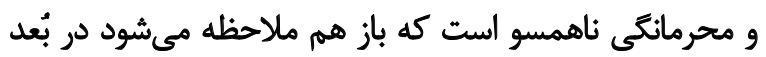

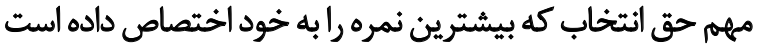

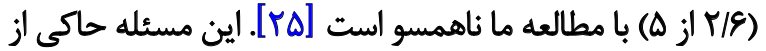

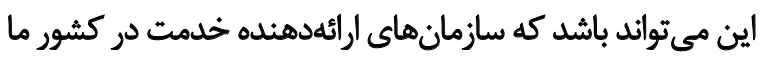

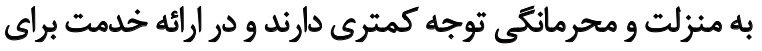

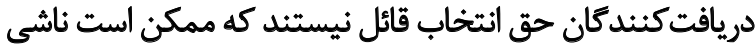


بيشتر به دنبال درمان و سلامتى هستند. در حالى كه افراد

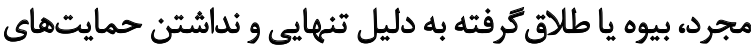

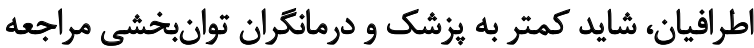
مي كنيند

بيشتر مراجعهكنيدكان از نظر تعداد اعضاى خانواده، به طور

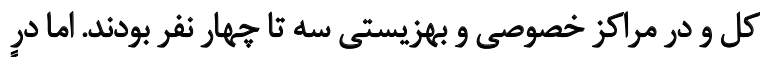

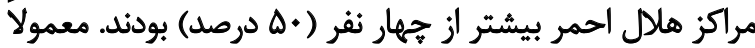

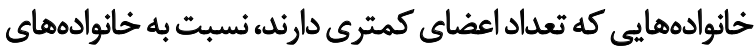

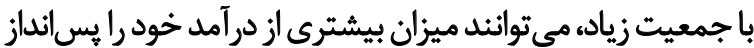

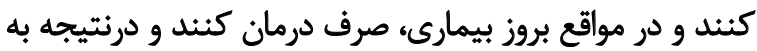
مراكز خصوصى مراجعه كنيند.

يرداخت هزينه بيشتر مراجعهنيندكان مراكز خصوصى،

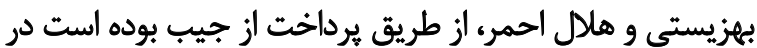

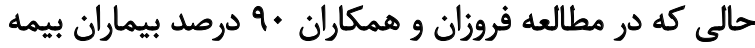

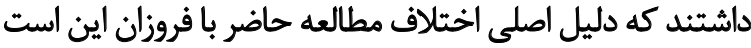

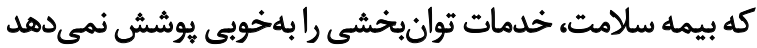

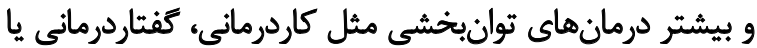

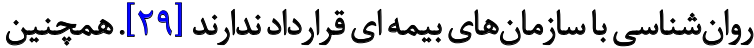

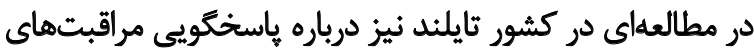

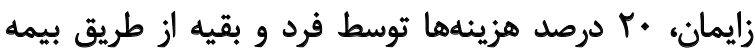

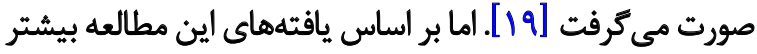

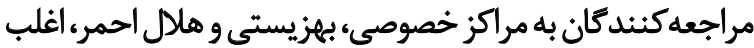

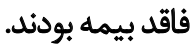

بيشتر مراجعهكنيندكان مراكز خصوصى، بهزيستى و هلال

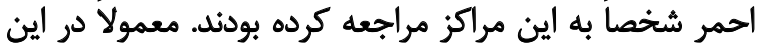

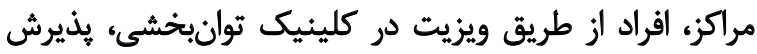

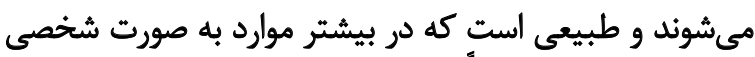

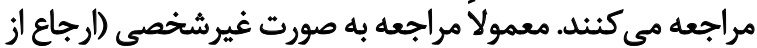

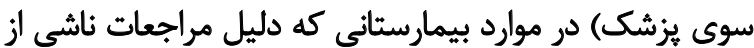

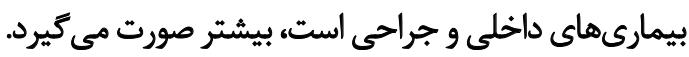
در مطالعه حاضر، بالهميت درين بُعد، از نظر مراجعه كنيندكان،

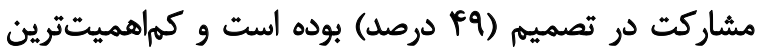

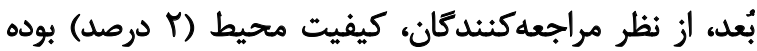

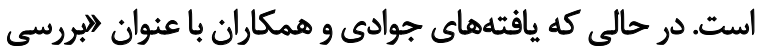

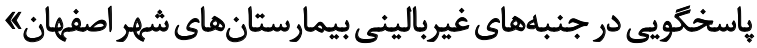

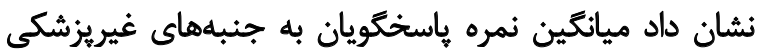

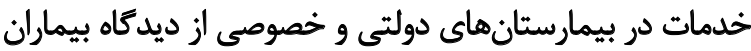

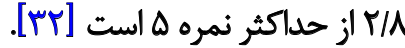

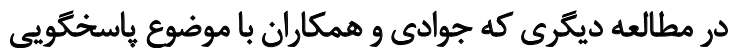

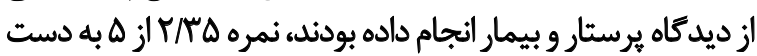

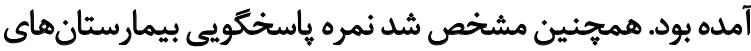

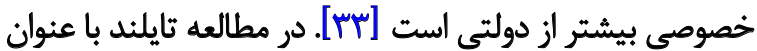

بهترين عملكرد ياسخخويى درباره بُعد حق انتخاب بود و بدترين

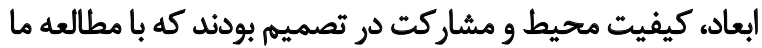

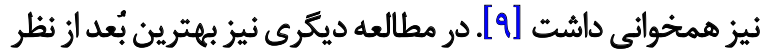

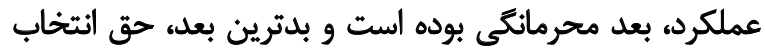

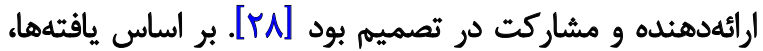

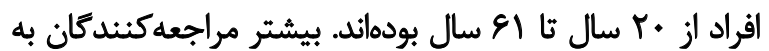

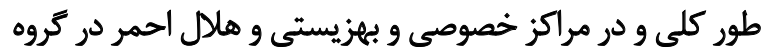

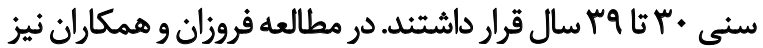

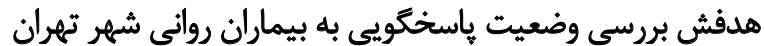

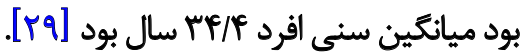

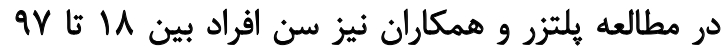

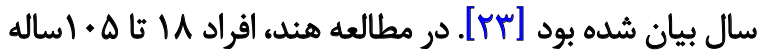

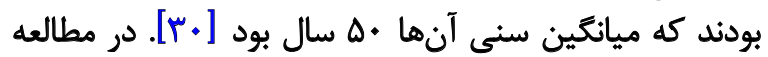

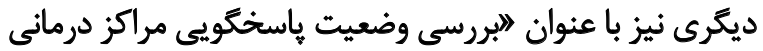

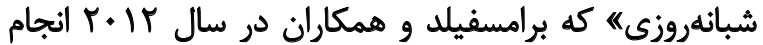

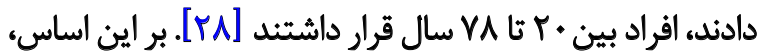

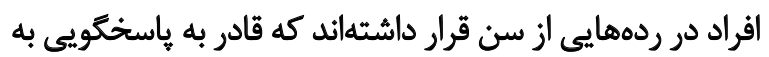

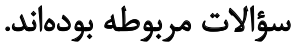

تفري اساس يافتهها، بيشتر مراجعلكنيندكان (از نظر جنسيت)، به

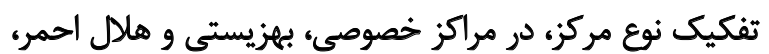

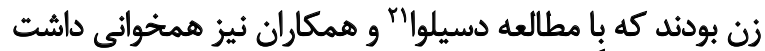

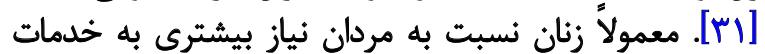

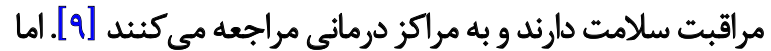

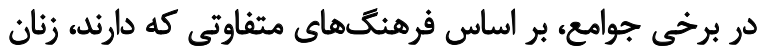

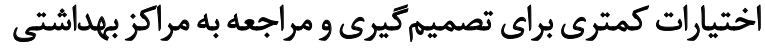

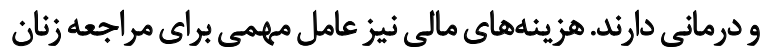

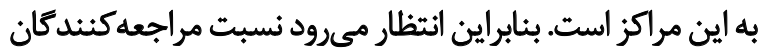

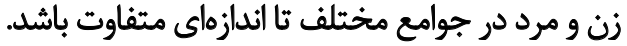

بيشتر مراجعهكنندگان به طور كلى و در مراكز بهزيستى و

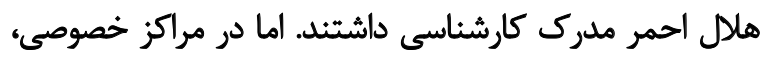

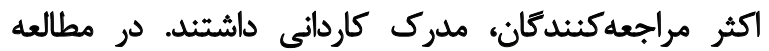

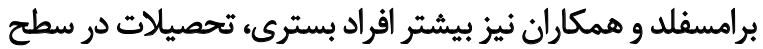

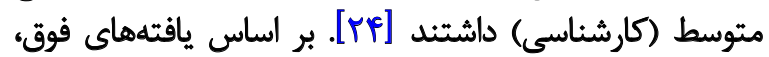

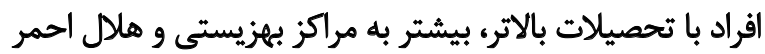

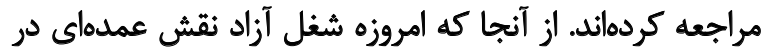

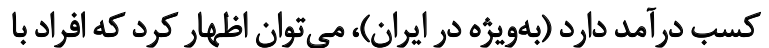

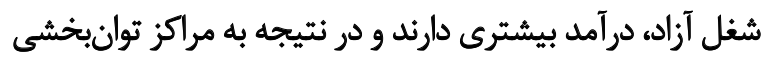
خصوصى مراجعه مى كنند.

بيشتر مراجعهكنيدكان در مراكز خصوصى، بهزيستى و هلال

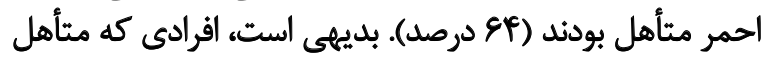

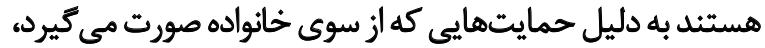

21. Desilva 
شده باشد كه اين ميثواند نقطه ضعف مطالعه باشد. بنابراين

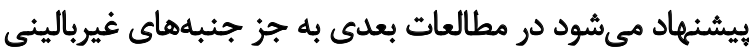

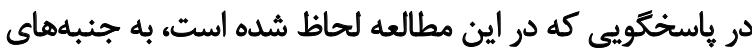
بالينى ارائه خدمات نيز توجه شودي

نتيجلهَيرى

نتايج اين يروهش نشان داد ياسخكويى به عنوان يك معيار

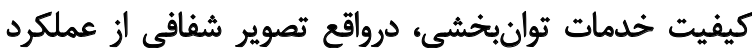

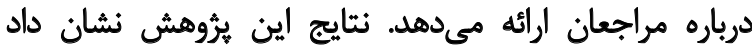

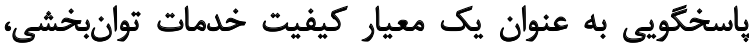
درواقع تصوير شفافى از عملكرد درباره مراجعان ارئي مئه مى دهد.

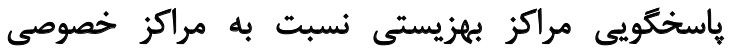

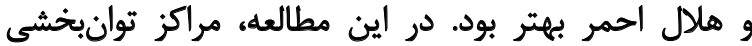

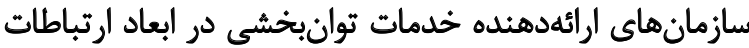

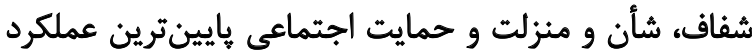

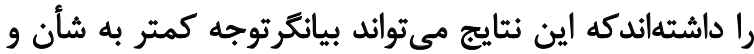

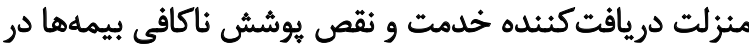

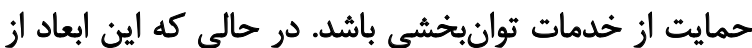

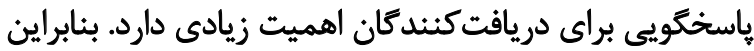

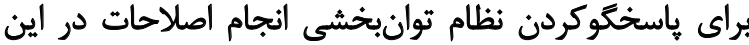

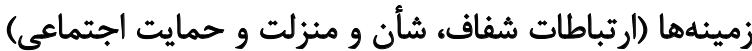

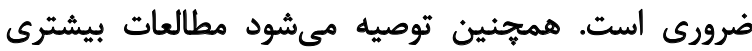
درباره ياسخكويى نظام توانبخشى صورت كيرد.

در اين مطالعه اكر جه بُعد حق انتخاب و كيفيت محيط از نظر

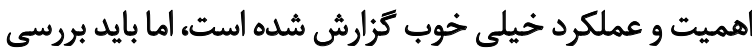

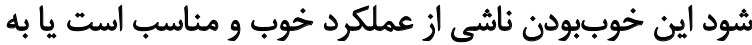

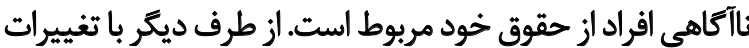

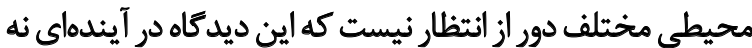

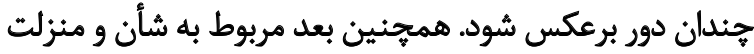

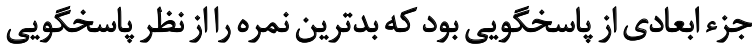

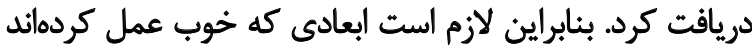

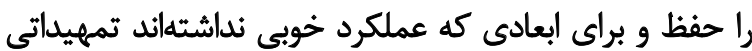

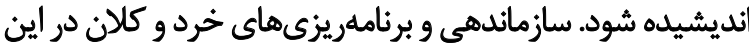

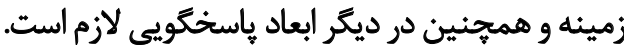

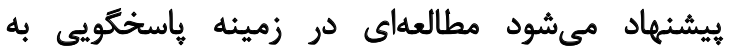

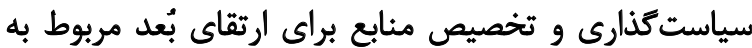

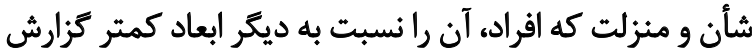

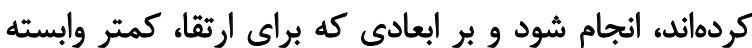

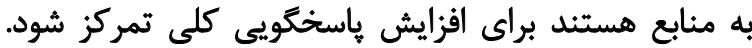

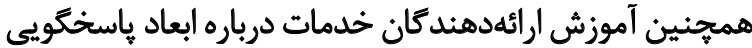

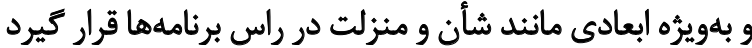

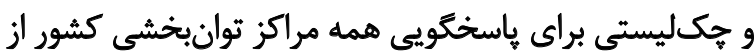
سوى سازمان بهزيستى يا وزارت بهداشت، برائ ارزيابي كيفيت مانيت

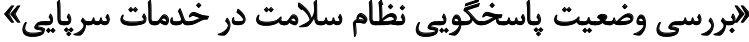

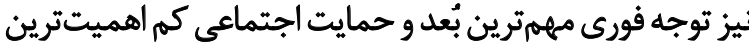

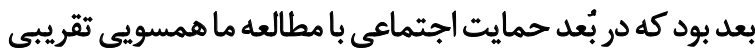

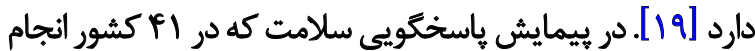

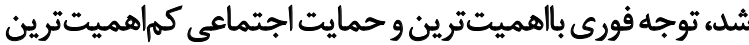

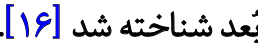

در مطالعه كورنوال "r و همكاران، بالهميتترين بعدئ كيفيت

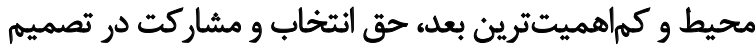

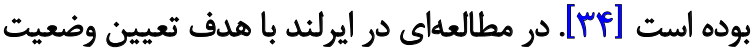

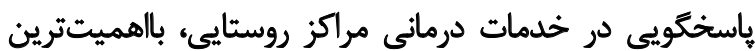

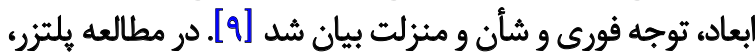

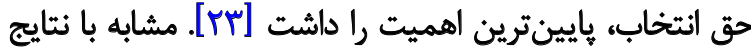

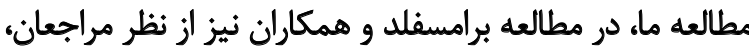

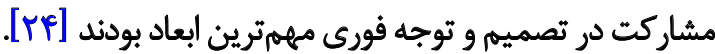

در مطالعه ديكرى كه در هند با هدف پايش نظائ نام سلامت

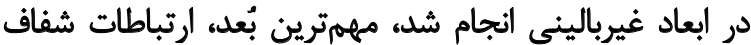

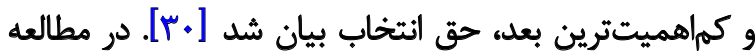

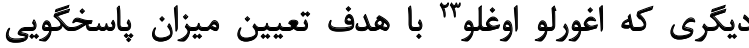

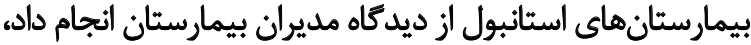

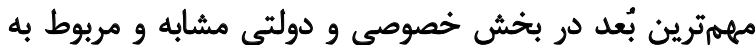

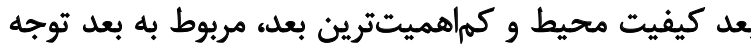

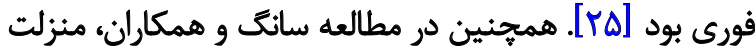

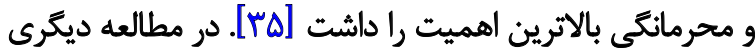

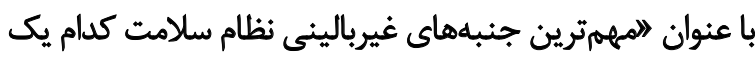

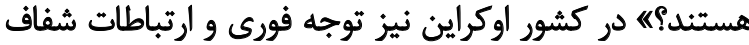

مهممترين ابعاد ثلقى شدند [19]

همجنان كه ملاحظه مي كنيد بُعد توجه فورى در بيشتر

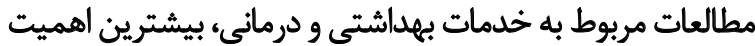

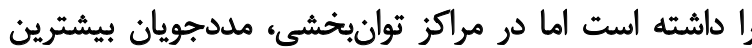

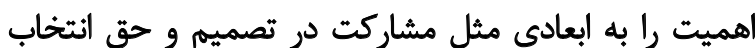

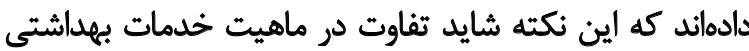

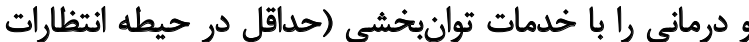
غير بالينى مددجويان) نمايان مى كندان

از نقاط قوت مطالعه، مي توان به اين موارد اشاره كرد: در اين

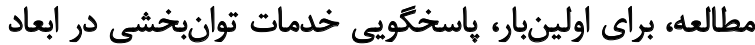

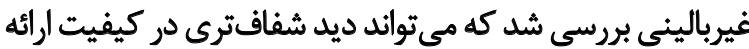

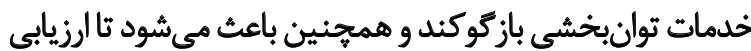

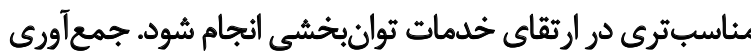

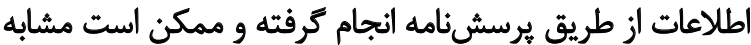
تمام مطالعات خوداظهارى باعث خطاهائ درئ در نتايج مطالعه

22. Cornwall

23. Oghlou 
ارائه خدمات و ارتقاى بهرهورى در دو جنبه مشترىمدارى و و مدات

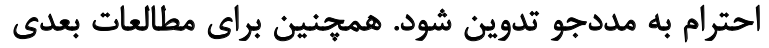

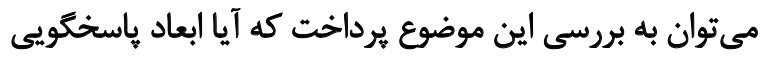

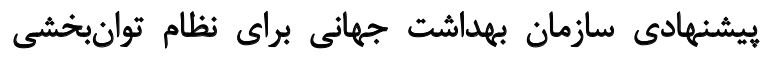
ايران مناسب است يا خير؟ إن

ملاحظات اخالاقي

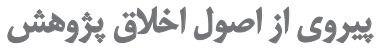

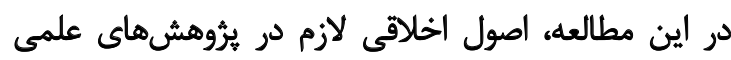

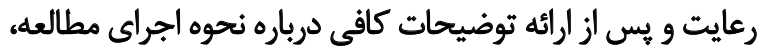

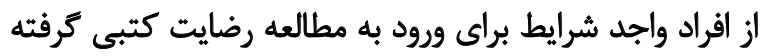
شد. اين مطالعه هيج هزينه مالى براى شركت كنيندكان نداشت

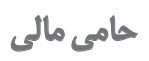

اين مقاله بخشى از باياننامه كارشناسىارشد نويسنده

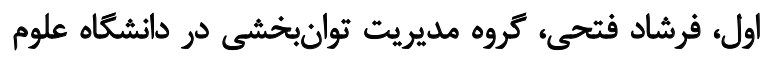

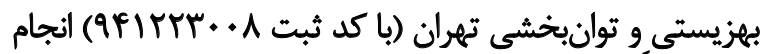
شد. ضمناً أين مقاله حامى مالى ندارد.

$$
\text { مشاركت ثويسند مكان }
$$

ايدهازي: فرشاد فتحى، كيانوش عبدى؛ مفهومسازي: فرشاد

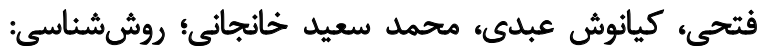

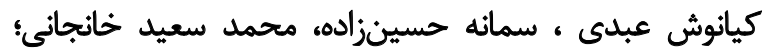

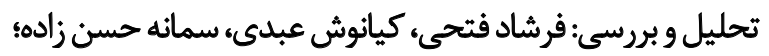

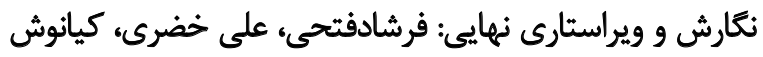

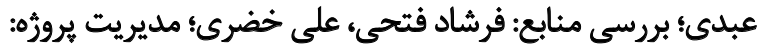

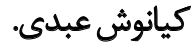

$$
\text { تعارض مناقع }
$$

بنابر اظهار نويسندكان، اين مقاله هيجكونه تعارض منافعى ندارد. 


\section{References}

[1] Ghobadian A, Speller S, Jones M. Service quality: Concepts and models. International Journal of Quality \& Reliability Management. 1994; 11(9):43-66. [DOI:10.1108/02656719410074297]

[2] Alonso A, Brugha R. Rehabilitating the health system after conflict in east timor: A shift from NGO to government leadership. Health Policy and Planning. 2006; 21(3):206-16. [DOI:10.1093/heapol/czl006] [PMID]

[3] Statistical Center of Iran, Population and housing census. [Internet] 2012 [Updated 2019 August 13]. Availble from: www.amar.org.ir

[4] Ahsan M, Ibrahimy Ml, Khalifa OO. Advances in electromyogram signal classification to improve the quality of life for the disabled and aged people. Journal of Computer Science. 2010; 6(7):706-15. [DOI:10.3844/jcssp.2010.706.715]

[5] Fabsitz RR, McGuire A, Sharp RR, Puggal M, Beskow LM, Biesecker LG, et al. Ethical and practical guidelines for reporting genetic research results to study participants: Updated guidelines from a national heart, lung, and blood institute working group. Circulation: Genomic and Precision Medicine. 2010; 3(6):574-80. [DOI:10.1161/CIRCGENETICS.110.958827] [PMID] [PMCID]

[6] Statistical Center of Iran. Population and housing census. [Internet] 2017 [Updated 2019 August 13]. Availble from: www.amar.org.ir

[7] Lindkvist L, Llewellyn S. Accountability, responsibility and organization. Scandinavian Journal of Management. 2003; 19(2):251-73. [DOI:10.1016/S0956-5221(02)00027-1]

[8] Fazaeli S, Ahmadi M, Rashidian A, Sadoughi F. A framework of a health system responsiveness assessment information system for Iran. Iranian Red Crescent Medical Journal. 2014; 16(6):e17820.[DOI:10.5812/ircmj.17820] [PMID] [PMCID]

[9] Valentine NB, de Silva A, Kawabata K, Darby C, Murray CIL, Evans DB. Health system responsiveness: Concepts, domains and operationalization. In: Murra y CJL, Evans DB, editors. Health Systems Performance Assessment: Debates, Methods and Empiricism. Geneva: World Health Organization; 2003.

[10] Murphy-Cullen CL, Larsen LC. Interaction between the sociodemographic variables of physicians and their patients: Its impact upon patient satisfaction. Social Science \& Medicine. 1984; 19(2):163-6. [DOI:10.1016/0277-9536(84)90283-1]

[11] Darby C, Valentine N, De Silva A, Murray CJ, Organization WH. World Health Organization: Strategy on measuring responsiveness. Geneva: World Health Organization; 2003.

[12] Murthy RK. Building women's capacities: Interventions in gender transformation. Thousand Oaks: Sage; 2001.

[13] Mahmudreza G, Jamalodin TS, Amirashkan N, Mohammad $M$. Seven dimensions of accountability in Iran's teaching hospitals: A national study. Payavard Salamat. 2012; 6(4):1-10.

[14] Leader N. Codes of conduct: who needs them? Relief and Rehabilitation Network Newsletter. London: Overseas Development Institute. 1999.
[15] Williams B. Patient satisfaction: A valid concept? Social Science \& Medicine. 1994; 38(4):509-16 [DOI:10.1016/02779536(94)90247-X]

[16] Valentine N, Darby C, Bonsel GJ. Which aspects of nonclinical quality of care are most important? Results from WHO's general population surveys of "health systems responsiveness" in 41 countries. Social Science \& Medicine. 2008; 66(9):1939-50. [DOI:10.1016/j.socscimed.2007.12.002] [PMID]

[17] Vitrai J. Inequalities in health systems' responsiveness: A joint World Health Survey report based on data from selected central European countries. Study report. Geneva: World Health Organization; 2007

[18] Murray CJL, Evans DB. Health systems performance assessment: Debates, methods and empiricism. Geneva: World Health Organization; 2003.

[19] Liabsuetrakul T, Petmanee P, Sanguanchua S, Oumudee N. Health system responsiveness for delivery care in Southern Thailand. International Journal for Quality in Health Care. 2012; 24(2):169-75. [DOI:10.1093/intqhc/mzr085] [PMID]

[20] Robinson P. Government accountability and performance measurement. Critical Perspectives on Accounting. 2003; 14(1-2):171-86. [DOI:10.1006/cpac.2002.1010]

[21] Edwards M, Hulme D. Non-governmental organisations: Performance and accountability: Beyond the magic bullet. Abingdon Routledge; 2014.

[22] Peters BG, Pierre J. Citizens versus the new public manager: The problem of mutual empowerment. Administration \& Society. 2000; 32(1):9-28. [DOI:10.1177/00953990022019335]

[23] Peltzer K. Patient experiences and health system responsiveness in South Africa. BMC Health Services Research. 2009; 9:117. [DOI:10.1186/1472-6963-9-117] [PMID] [PMCID]

[24] Bramesfeld A, Wedegärtner F, Elgeti $\mathrm{H}$, Bisson $\mathrm{S}$. How does mental health care perform in respect to $s$ ervice users' expectations? Evaluating inpatient and outpatient care in Germany with the WHO responsiveness concept. BMC Health Services Research. 2007; 7:99. [DOI:10.1186/1472-6963-7-99] [PMID] [PMCID]

[25] Peltzer K, Phaswana-Mafuya N. Patient experience and health system responsiveness among older adults in South Africa. Global Health Action. 2012; 5(18545):1-11. [DOI:10.3402/gha.v5i0.18545] [PMID] [PMCID]

[26] Hüpkes E, Quintyn M, Taylor MW. The accountability of financial sector supervisors-principles and practice. European Business Law Review. 2005; 16(6):1575-620.

[27] Rashidian A, Kavosi Z, Majdzadeh R, Pourreza A, Pourmalek $F$, Arab M, Mohammad K. Assessing health system responsiveness: a household survey in 17th district of Tehran. Iranian Red Crescent Medical Journal. 2011; 13(5):302-8. [PMID] [PMCID]

[28] Bramesfeld A, Klippel U, Seidel G, Schwartz FW, Dierks ML. How do patients expect the mental health service system to act? Testing the WHO responsiveness concept for its appropriateness in mental health care. Social Science \& Medicine. 
2007; 65(5):880-9. [DOI:10.1016/j.socscimed.2007.03.056] [PMID]

[29] Forouzan AS, Ghazinour M, Dejman M, Rafeiey H, San Sebastian $\mathrm{M}$. Testing the WHO responsiveness concept in the Iranian mental healthcare system: A qualitative study of service users. BMC Health Services Research. 2011; 11:325. [DOI:10.1186/1472-6963-11-325] [PMID] [PMCID]

[30] Malhotra C, Do YK. Socio-economic disparities in health system responsiveness in India. Health Policy and Planning. 2012 28(2):197-205. [DOI:10.1093/heapol/czs051] [PMID] [PMCID]

[31] De Silva A, Valentine N, World Health Organization. Measuring responsiveness: Results of a key informants survey in 35 countries. Geneva: World Health Organization; 2000.

[32] Javadi M, Yaghoobi M, Raiesi A, Mandegar, Ayoobian A. [A study of non-medical aspects of health services provided to patients in selected hospitals of Isfahan: Responsiveness (Persian)]. Health Information Management. 2011; 8(5):709-17.

[33] Javadi M, Karimi S, Raiesi A, Yaghoubi M, Shams A, Kadkhodaie $M$. [Organizational justice and responsiveness in selected private and public hospitals of Isfahan, Iran (Persian)]. Journal of School of Public Health and Institute of Public Health Research. 2012; 9(4):11-20.

[34] Cornwall A, Lucas H, Pasteur K. Introduction: Accountability through participation: Developing workable partnership models in the health sector. IDS Bulletin, 31(1):1-13. [DOI:10.1111/j.1759-5436.2000.mp31001001.x]

[35] Peng D, Li XS, Zhang Q, Zhu CR, Zhang JY, Yuan P, et al. [Responsiveness evaluation of mental intervention services system in Wenchuan earthquake area (Chinese)]. Chinese Journal of Preventive Medicine. 2011; 45(2):158-62. 